\title{
Women's perceptions of sexuality in rural Giza
}

Hind Khattab

Follow this and additional works at: https://knowledgecommons.popcouncil.org/departments_sbsr-pgy

Part of the Demography, Population, and Ecology Commons, Gender and Sexuality Commons, International Public Health Commons, and the Women's Health Commons How does access to this work benefit you? Let us know!

\section{Recommended Citation}

Khattab, Hind. 1996. "Women's perceptions of sexuality in rural Giza," Monographs in Reproductive Health. Cairo: Reproductive Health Working Group. 


\section{HIN D KHATTAB}

\section{Reproductive Health Working Group} The Population Council Regional Office for West Asia and North Africa, Cairo 


\section{Women's Perceptions Of Sexuality in Rural Giza}

\section{HIND KHATTAB}

(3)

MONOGRAPHS IN REPRODUCTIVE HEALTH NO.1 1996

$$
\text { (1)., (2), (3) }
$$

p

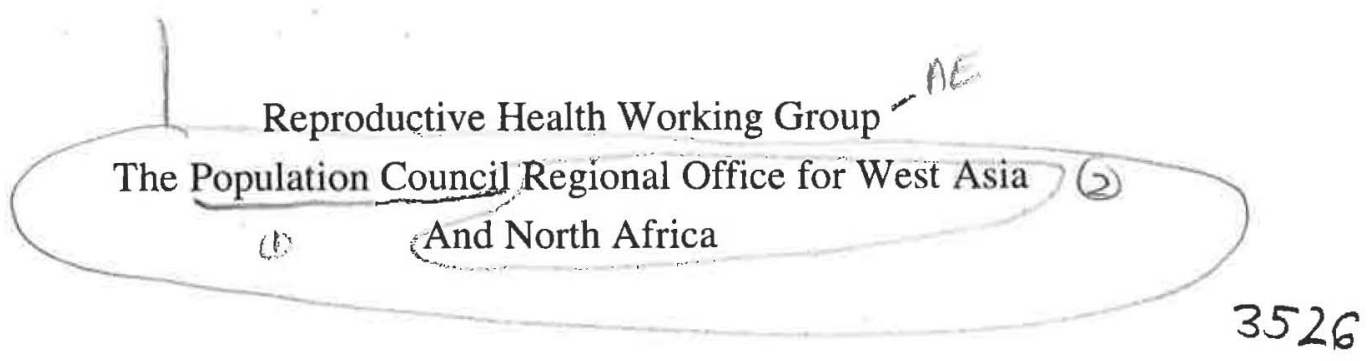


The Population Council seeks to improve the well-being and reproductive health of current and future generations around the world and to help achieve a humane, equitable, and sustainable balance between people and resources.

The Council, a nonprofit, non-governmental research organization established in 1952, has a multinational Board of Trustees: its New York headquarters supports a global network of regional and country offices.

The Policy Series in Reproductive Health is produced by the Reproductive Health Working Group housed in the Population Council Regional Office for West Asia and North Africa, P.O.Box 115, Dokki, Giza, Egypt.

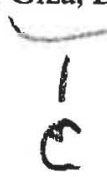

(C) Copyright 1996

The Population Council

ISBN: $977-5563-10-0$

Cover Design \& Consultant: Fadia Badrawi

Printing Supervision: NOUR -Arab Women's Publishing House 


\section{TABLE OF CONTENTS}

Preface

Foreword

Acknowledgements

I. INTRODUCTION

II. METHODOLOGY 6

$\begin{array}{ll}\text { III. FINDINGS } & 11\end{array}$

$\begin{array}{ll}\text { Perception of Sex Difference } & 11\end{array}$

$\begin{array}{ll}\text { Menstruation } & 12\end{array}$

$\begin{array}{ll}\text { Female Circumcision } & 16\end{array}$

Perception and Attitude Towards Virginity 21

Marriage and Initiation of Sex Relations 23

$\begin{array}{ll}\text { Women's Perception of Body Organs } & 26\end{array}$

Knowledge of Physiology of Reproduction 28

Talking about Sexual Activity $\quad 29$

$\begin{array}{ll}\text { Libido } & 31\end{array}$

Wives' Perception of Husbands' Right to Sex 34

Attitude to Sex Practice $\quad 37$

$\begin{array}{ll}\text { Extra-Marital Relations } & 37\end{array}$

Homosexuality $\quad 40$

Linking Reproductive Tract Infections to Sexuality 41

IV. SUMMARY AND CONCLUSIONS

$\begin{array}{ll}\text { References } & 49\end{array}$ 


\section{PREFACE}

\section{Monographs in Reproductive Health}

Monographs in Reproductive Health aim at sharing research and analysis undertaken by members of the Reproductive Health Working Group with the wider research community. The Reproductive Health Working Group was established in 1988 as part of a Special Program on the health of women and children within the context of the family and community initiated by the Population Council's Regional Office for the West Asia and North Africa (WANA) region. The Working Group includes professionals with specializations in anthropology, biostatistics, demography, medicine, public health and sociology, residing in various countries of the region.

The Working Group delineated three key issues which were considered as central to women's reproductive health in the WANA region: first, women's physical health in terms of morbidity conditions related to the reproductive function; second, women's perceptions of their health and their dignity in relation to reproduction; and third, on the health service side, the quality of reproductive health services directed at women. The Working Group has been undertaking studies addressing these issues in countries of the region since 1989. Further research interests are currently emerging concerned with developing an intervention framework to improve reproductive health within primary care settings, and with investigating physicians' perceptions of women's health.

Monographs in Reproductive Health and the Policy Series in Reproductive Health are two complementary publications issued by the Reproductive Health Working Group. Papers in the Policy Series in Reproductive Health reach out with frameworks, methodologies and evidence of research to policy makers, program managers and health advocates. They aim to contribute to the development of more holistic policy approaches to women's health. Monographs in Reproductive Health address researchers and students primarily, and aim to cross disciplinary lines. They present original research, reviews of literature and theoretical discussions on subjects of interest to one discipline, of medical or social sciences, bringing concepts and results into the realm of understanding and interest of the other. In this way the Monographs in Reproductive Health aim to contribute to the advancement of interdisciplinary approaches in research on women's reproductive health. 
FOREWORD

In the context of Egyptian society, sociomedical research on sexuality has stressed certain assumptions:

First: Rural Egyptian women do not really have problems related to sexuality.

Second: If they have problems, these women do not like or want to talk about them. Third: Islamic tradition bans any discussions in these problems.

These assumptions have led to a wide gap in studies concerning women's perceptions of sexuality and sexual problems. Here is a study which challenges these assumptions

Dr. Khattab's study proves that problems related to sexuality do exist and bother rural women in Egypt. Once rapport is established, discussing sexuality is not a taboo among rural women. Women could frankly talk about their sexual concerns and fears to someone who knows and cares.

Islam is understanding of women's needs concerning sexuality. Islamic teaching can provide a context within which education about sexuality can be approached in Egyptian culture.

I am sure that both biomedical and social scientists will find this book of great value. I am indeed privileged to be invited to write the foreword to this study on sexualtity.

Nabil Younis

Faculty of Medicine $\mathrm{Al}$-Azhar University 


\section{ACKNOWLEDGEMENTS}

I gratefully acknowledge the assistance provided by many people and institutions who have contributed directly and indirectly to make this document possible.

The Population Council not only initiated the Reproductive Morbidity Project, but offered support to the research from which this book emanated. Financial support at various stages in preparation for this document was provided by the Ebert Program of the Population Council, New York.

For encouragement, critical comments and suggestions, I want to thank the friends and colleagues who pointed to fruitful directions and helped revise version after version of the manuscript. Particularly helpful were Dr. Huda Zurayk (The Population Council, Cairo), Dr. Nabil Younis (Al Azhar University) and Ms. Judith Bruce (Ebert Program, The Population Council, New York). I would like to extend my appreciation and thanks to Ms. Jan Amin who edited the document. Her advice and comments on this book were invaluable.

Without the staff of Delta Consultants, who worked hard to bring this manuscript into being, this book would not have been written. I am thankful to Nadine Karraze, Olfia Kamal, Sahar Fathi, Omaima Zikrallah, Eman Saleh, Yousriya Sa'ad, Amira Ahmed and Hana'a Abdel Fattah. 


\section{INTRODUCTION}

This study on sexuality among a group of women in rural Giza in Egypt is part of a broader project on women's health and reproductive morbidity conducted by the Reproductive Health Working Group ${ }^{(1)}$ (The Giza Reproductive Morbidity Study 1989-1990). Reproductive health is defined by the Group as "the ability of women to live from adolescence or marriage with reproductive choice, dignity and successful childbearing and to be free of gynecological disease and risk" (Fathalla 1988; Germain 1987; Evans et al. 1987; Working Group on Reproductive Health 1988; Zurayk 1988). Among the important factors influencing the reproductive health of women is the multiplicity of roles they perform as wives, mothers, wage-earners, and caregivers, and the interaction of these roles with their socio-economic status, and the cultural factors which influence their beliefs and perceptions. Prevailing cultural beliefs and practices - directly and indirectly - affect women's health. Consequently, women's perceptions of their bodies and of their health shape their health-seeking behavior and their health practices.

Reproductive tract infections and other ailments associated with reproduction among women in the rural community surveyed (Younis et al. 1993) suggest that a heavy burden of disease is being borne by women living in underprivileged areas of our region. The vast majority of women in the Giza villages are shown to be suffering from at least one gynecological or related morbidity. In particular, reproductive tract infections (RTI) affect fifty-one percent of the total sample of five hundred and nine women. Vaginitis was found to be prevalent in forty-four percent, bacterial vaginosis

1) The Population Council in the West Asia and North Africa Region began in 1987 a program of research and technical consultation in child survival, reproductive health and family resources for health. The program established three working groups of regional scholars to develop and implement research agendas in the three areas of the program. In the area of reproductive health the Reproductive Health Working Group tackled three subjects: 1) Reproductive morbidity, including both obstetric and gynecological morbidity, 2) Quality of care of reproductive health services, 3) Women's dignity as a concept that can help to explain women's reproductive behavior in the Region. 
in twenty-one percent, trichomonas in eighteen percent and candida in eleven percent (Younis et al. 1993). Some of these reproductive tract infections are sexually transmitted. A woman is exposed to certain sexually transmitted diseases not necessarily because of her own sexual behavior but rather, in the majority of cases, her husband's. In the Giza sample, sexually transmitted diseases identified among women were trichomonas (18\%), Chlamydia (9\%) And syphilis (4 cases) (Younis et al. 1993).

The high prevalence of reproductive morbidity is certainly disabling to women in the study community; it raises great concern about the physical and social well-being of women as RTI's are known to cause physical discomfort, personal embarrassment, and marital discord, and to affect a woman's ability to achieve and sustain a pregnancy, and to give birth to a normal weight baby (Wasserheit 1990). The high percentage of sexually transmitted diseases was among the reasons which generated an interest in conducting research into sexual behavior.

It is within a conceptual framework that uses a socio-cultural approach to health and illness that this research on sexuality has been conducted. The investigation is an assessment of women's perception of and knowledge about sexuality and various body organs and their functions, and the ability of these women to relate these functions to reproductive tract infections and other morbidities. Very few studies concerned with health and illness have used a multidisciplinary approach, in which a group of researchers including health-care providers and social scientists work together to develop a definition of health from the perspective of both providers and users, and to design a framework and operational instruments that represent both perspectives.

Contemporary published research on sexuality falls into two distinct categories. One is medical research interested in the etiology of diseases associated with sexuality (venereal diseases, etc.) and the other is social research investigating sexuality as a social phenomenon. In terms of medical research, since the early 1940's (Kinsey et al. 1948;1953) teams of physicians, psychotherapists and sexologists have been investigating and classifying reactions of the human body and organs to sexual stimuli for the 
purpose of establishing a standard taxonomy of sexual functioning in the human body. Observing sexuality from a biomedical perspective (Masters et al. 1966) the scientific community legitimized the analysis of sexuality, including sexual behavior, as opposed to nineteenth century studies in which the subject of sexuality was studied in relation to reproduction alone because of moral and religious contingencies (Weeks 1977;1981).

In the domain of social science, the study of sexuality was traditionally conducted by anthropologists who were interested in investigating and analyzing socio-cultural factors surrounding sex behavior. Two theoretical currents in social science and anthropology have investigated sexual behaviors and their meaning in different societies. An informative article by Carol Vance (1991) presents these two perspectives. The cultural influence model of sexuality emphasizes "..the role of culture and learning in shaping sexual behavior and attitudes". As illustrated by research beginning in the early twenties by anthropologists, "..sexuality is assumed - and often quite explicitly stated - to be universal and biologically determined" (Bateson 1947; Malinowski 1929; Mead 1923; Murdock 1949). The second theoretical perspective called social construction "..examines the range of behavior, ideology and subjective meaning among and within human groups, and views the body, its functions, and sensations as potentials (and limits) which are incorporated and mediated by culture" (Peiss et al. 1989; Weeks 1981).

During the 1980's and 1990's a resurgence of sexually transmitted diseases, and specifically AIDS, has alerted the scientific community to the need to pursue research in the medical sphere and investigate the socio-cultural mechanisms that shape individuals' beliefs and practices that influence sexual behavior. AIDS is a disease transmitted mainly through sex behavior, and in the absence of either a vaccine or a cure for the disease, prevention so far has relied heavily on the change of social behavior, which in this case is sexual behavior. While this new virus has presented many unique challenges to health professionals and providers, it has also revealed many subsisting problems of power relations, inequality and the taboo of sexuality (Elias 1991). Heterosexual transmission of HIV is emerging as the dominant form 
of transmission (Elias 1991), and in third world countries women are among the most exposed to sexually transmitted diseases. What makes their situation even worse is the lack of power over their own decision-making concerning both sexual behavior and health- seeking behavior. In many of these communities cultural stigmatization of sexually transmitted diseases combined with the dependency and inferior social position women have, deny them access to information concerning reproductive health in general and reproductive tract infection in particular. Because prevailing cultural beliefs and practices surrounding health and illness ultimately influence women's health, there is a need to investigate and analyze the cultural dynamics which help shape the beliefs and practices of women concerning sexuality and related health problems. This was the approach adopted in undertaking the study of sexual behavior in the Giza villages in rural Egypt.

In the context of Egyptian society, religion (Islam is the religion of the majority) is a fundamental part of culture which shapes the daily lives of individuals. Islam not only provides doctrines (Ebadat), but offers also a style and a mode of life for Muslims to follow, covering all aspects of relationships including the domain of sexuality. Hence, in order to understand women's perception and beliefs regarding sexuality in an Egyptian rural community, one has first to learn about the precepts of Islam concerning this issue. In Islam, for instance, relations between men and women are based upon complementarity. The Qur'an states, "They (women) are your garments and ye are their garments" (El Bakara S.2, V. 187). Several sayings of the Prophet Mohamed (Hadith) indicate clearly that Islam acknowledges the right of both men and women to sexual fulfillment. "When you copulate with your wife do not leave her until she is fully satisfied like you" (Khatib 1950). In Islam sexuality is legitimized only within the institution of marriage. This is supported by a Hadith stating : "The man who marries takes possession of half of his religion". Thus in contemporary Islamic societies women's perception of sexuality is confined to the institution of marriage, which is reinforced through socialization, formal education, and religious teachings; any extramarital or premarital relations are reprehensible and shameful. Divorced and widowed women are 
also forbidden to be sexually active as long as it is not within a legalized relationship. In Islam equal punishment is applied to both men and women in the context of adultery, although existing norms in the same societies are more tolerant with male premarital or extra-marital relations, and women are more severely punished than men. Thus some of the civil laws in some of the countries in the region contradict the jurisdiction of Islam concerning adultery. These civil laws were borrowed from Western civil laws early in this century.

Unlike other religions, Islam does not surround sexuality with feelings of sinfulness or guilt, hence, no curse is involved. Moreover, Islam does not confine sexuality to the purpose of procreation, but acknowledges physical love for enjoyment. The Qur'an abounds in verses describing the genesis of life based on copulation and physical love. "Your Lord", says the Qur'an, "created you of a single soul, and from it created its mate and from the pair of them scattered abroad many men and women" (S.4, V.1). In one instance, the Prophet is reproached by God for intending to go on a sexual strike against his wives as a result of certain domestic problems. "Prophet! Why Holdest thou to be forbidden That which God has Made lawful to thee? Thou Seekest to please Thy consorts. But God Is Oft-Forgiving, Most Merciful" (S.66, V.1). This Verse indicates that sexuality is not limited to procreation but is there for enjoyment and pleasure.

Universally, cultures are organized around social systems which influence normative beliefs, behaviors and practices. In turn these norms influence peoples' perceptions of sexuality. In the case of rural Egypt knowledge about sexuality is acquired rather early in life (Khattab 1983). Children are exposed to sexuality either because of the living patterns within the household (children share the parents' bedroom), or because they observe the sexual behavior of animals around them. In the past, dissemination of information regarding tradition, values, mores and the facts of life, including sexuality, were passed from one generation to the successive generation through the family; the dominant role of the family was asserted through the upbringing, socialization of and discussion with the younger generation. However, in the last thirty years this pattern of culture transmission has 
undergone radical changes resulting from the emergence of other institutions and of social changes, such as the spread of education and schooling for both sexes, rural/urban migration, labour migration to Arab countries, and the increasing exposure to mass media. Meanwhile, the pattern of passing information from one generation to the next was also gradually replaced by peer group discussion, as a result of being increasingly in contact with each other through schooling and work. However, the youth are still exposed to adults' comments and jokes surrounding sexuality. Consequently, children's conversations and verbal exchanges often include jokes and innuendoes on sexuality, not only implying knowledge about sexuality but also indicating that the subject is not taboo.

\section{METHODOLOGY}

The field research for the Giza Reproductive Morbidity Study was conducted in two villages in rural Giza (adjacent to Cairo) in 1989 - 1990. One village has an estimated population of twelve thousand people and the second four thousand five hundred people. Each has a health center managed by a female general practitioner, and both share primary and preparatory schools. Illiteracy is quite high in this community especially among women (eighty two percent of ever-married women in the study sample). Agriculture is the major occupation for both genders. However, other occupations such as manufacturing, transport, commerce and services are also common.

Eligible women for the study were defined as ever-married and residing in one of the two villages. Age quotas were determined to make the distribution of the sample similar to that in the population as indicated by the most recent census results. A sample of five hundred and nine women was selected using random techniques and based on a geographical mapping of the villages. (For more information on the sample and the study see Younis et al. 1993)

When the initial results of the Giza Reproductive Morbidity Study indicated 
a high prevalence of sexually transmitted diseases among the women respondents, it was deemed essential to investigate the issue of sexuality, especially that a health education intervention package was being prepared $^{(2)}$. The sexuality study aimed at gaining insight into the knowledge, perception and practices of rural women concerning sexuality, and at findingout whether the women would be willing to answer sensitive questions frankly expressing their perceptions and views about personal experiences. The scope of the study on sexuality was to investigate women's perceptions of their body functions, and to learn about their perceptions of sexuality, that is, their beliefs and behaviors at different stages of their sexual life. In other words, we wanted to understand the interplay between cultural values, including religious beliefs, and the sexual behaviors and attitudes of women. Furthermore, we wanted to investigate women's awareness of the relationship between sexual practices and certain reproductive tract infections since these are often related.

\section{Sample}

In order to cover the maximum variability within the community under research a stratified sample was selected from among the sample of women of the Giza Morbidity Study. It included women who had contracted sexually transmitted diseases, women with other reproductive tract infections and a group free of disease and infection. Women

2) The initial analysis of the qualitative data on women's knowledge and perception of health in relation to the environment, indicated the lack of knowledge among interviewed women concerning the following areas: 1)reproductive tract infection especially STDs; 2) when and where to go for help; 3) fertility, infertility and contraception; 4) menarche and menopause; 5) adolescence, etc. Hence, the Giza Reproductive Morbidity Project was concerned with developing health information messages addressing illiterate women regarding their reproductive health. These messages were to be used as an educational tool in a later phase. Health information messages were designed for the educational intervention program. The medical information was gathered, put into colloquial Arabic, reviewed by the medical advisor and pretested. Furthermore, appropriate methods of communication were identified in order to disseminate the health information to village women. 
were also chosen from different age groups to further represent the community at large.

Forty-three women were selected to participate in this sexuality study, and only two did not continue in the study. The refusals came after the researchers made a number of visits. In fact, none of the women openly refused to participate. In one instance where the woman was one of the Syphilis cases, (the wife and the husband had been given treatment during the course of the Reproductive Morbidity Study), it was the husband who approached the social researchers and asked them not to contact or speak to his wife again. The husband's reluctance to allow his wife to participate in the sexuality study indicates awareness of his responsibility in contracting and transmitting the disease to his wife. In the second instance, the woman denied her presence and availability at home during six consecutive visits attempted by the research team. This woman was also a Syphilis case. It was quite obvious that both the woman and her husband were aware of the disease they had, because they had taken the medication prescribed in the course of the Reproductive Morbidity Study and had undertaken a second laboratory test.

Regarding the subject of the research, not all women responded to all questions, hence, numbers will not necessarily add up to the achieved sample of forty-one. The age range of the women in the sexuality study is between seventeen and forty-three years. Twelve women were under the age of twenty-five, twenty-three women were between twenty-five and thirty-nine, and six women were forty or more. Their husbands' ages ranged between mid twenties to late fifties: eleven men were less than thirty years old, fifteen aged between thirty and thirty-nine, nine men were between forty and forty-nine, and six men were fifty or more. Thirty-four among the forty-one women were illiterate (82.9\%), only three women had completed primary level schooling, another three had completed intermediate level and one woman was a holder of a university degree. Formal education among husbands shows that twenty-four were illiterate, six could read and write, four had completed primary level and seven were holders of secondary, intermediate or university degrees. 
With regard to occupation, most of the women in the sexuality study were housewives (twenty-three women), nine women worked in agriculture as unpaid family help, six worked as vendors (vegetable, poultry, grocery, stationary), two as dressmakers and one as a government employee. On the other hand, sixteen husbands were working in agriculture, five were government employees, six were vendors, eight were unskilled labourers, five were drivers and one was a car dealer.

The community under study represents the socio-economic milieu typical of rural areas in the Giza Governorate. The sexuality sample reflects the same socio-economic situation prevailing in this particular village and other villages of the same Governorate. Only two women of our sample came from a relatively high socio-economic background, the remaining group either belonged to the middle class within the rural context, or lived on a barely subsistence level.

\section{Data Collection}

Because the Giza Morbidity Study was the first study in Egypt conducted on reproductive morbidity at the community level, the researchers had made a special effort to ensure confidentiality and privacy of the interviews. This approach proved to be successful because when women were later asked to discuss sexuality, they did not shy away, some even volunteered information that was not solicited, and some women talked about certain issues on sexuality the research group did not put forward at the beginning, but was able to include later. The interviewed women were already familiar with the research team and had had ample time to establish a rapport of trust and credibility with the fieldworkers (Khattab et al. 1994). This had a positive influence on the amount and quality of data gathered. Although the research team made sure that the interviews on sexuality were conducted in total privacy and the information collected was kept confidential, some women used to invite friends and women relatives to the interviews and to participate in the discussions and share their information with the fieldworkers. Such an openness in discussing private issues among themselves reinforced the belief that, at least among women, there is no 
taboo to discussing and sharing experiences, beliefs and behavior in matters of sexuality.

The sequencing of topics for discussion was carefully planned basing it on the life-cycle of women to facilitate discussion on a delicate and private subject. The topic of menstruation was taken up first, then female circumcision, marriage ceremonies and deflowering, knowledge of body and the physiology of reproduction, sexual relations (initiation and enjoyment of the sexual act), and finally, sexuality and disease.

In order to facilitate discussion on sexuality more than twenty visits (one to three hours each) were conducted with each woman in the study, and additional information was collected on household organization and family relations to further understand the interplay between the socio-economic and environmental contexts and sexual beliefs and practices. All material discussed was recorded verbatim and later analyzed. Moreover, continuous exchange between the research group and the women in the community on various health issues including sexuality underlined a sense of familiarity and intimacy. Sometimes, women would ask the researchers for advice or clarification on certain sexual matters. This attitude provided further indication that women's perception of sexuality and sex behavior is not repressed or subdued by cultural norms.

Collecting such sensitive data, nevertheless, required very careful training of the social researchers, who assisted in the data collection. The training took place before and during the actual interviews. Four social researchers were trained by the anthropologist in how to ask questions of a private nature, how to direct the conversation so as not to diverge into side issues, especially when outsiders or in-laws participated in the conversation. When a woman did not want to continue with the discussion in the presence of outsiders, she would postpone the interview and ask the researcher to come at a later time. But in the majority of cases women did not mind carrying on conversations in the presence of other female members of the family. Training was also done on how to record information and observation immediately after interviews. The social researchers reported daily to the anthropologist and discussed the difficulties and problems they encountered 
so as to find solutions. As such some questions were rediscussed and elaborated on, following feedback from the interviewees and key informants. In general the majority of the women interviewed were very cooperative and extremely friendly toward the researchers. Knowing that some of the researchers were not married, some interviewees went so far as to tease them, claiming that the information they gave them should be considered part of their training in family life!

\section{FINDINGS}

\section{Perception of Sex Difference}

An ability to differentiate between the sexes is the first step towards gender identity and role differentiation, the awareness of sex difference starts with knowing the biological differences and leads to realizing the complementarity of the sexes, which is later followed by learning the facts about sexuality. For instance, when children say I will marry, their perception on the complementarity of the sexes for marriage is well established, because boys will always mention girls' names and vice versa, they never use the same discourse about a child of the same sex. However, knowledge of facts on sexuality comes at a later age.

Respondents were asked at what age they believed or had noticed that children (boys and girls) start to recognize the difference between the sexes. The majority of women (thirty-three out of forty-one) reported that children recognize the difference before they reach the age of seven. The remaining eight respondents said that children start to recognize the difference between the sexes around the ages of eight to ten, a few years prior to reaching puberty. Most women reported to have recognized the differences between the sexes before they were ten years old. The older respondents came to know at a later age, as compared to younger ones. Most women agreed that present-day children are more aware of sexuality than the previous generation. 
As far as puberty was concerned, it was easier for women to identify the age of puberty for girls than for boys. Puberty among girls, they reported, occurs between the ages of eleven and fifteen. Girls show more noticeable and obvious signs of puberty than do boys. Respondents claimed to know when girls are approaching puberty by signs of growing breasts and the appearance of pubic and underarm hair. Then they expect the onset of menarche. They believe that boys, on the other hand, reach puberty at a later age. Moreover, the signs are not as obvious and they occur gradually, hence are not as noticeable. When women were asked how they recognize that their sons have reached puberty, the large majority (thirty-seven out of forty-one) said they noticed the physical and bodily changes that the boys experience during this period such as growing in height, hoarseness in their voices and growing a moustache. A few women mentioned that some physical symptoms they look for when they want to know if their sons have reached puberty are semen ejaculation in their underpants before washing them. They feel that wet dreams are a sign of puberty. Other women said, "When my son starts talking about girls and how beautiful they are I know he is growing up", another said, "Once my son says I want to marry, I know he is pubescent". Yet another said, "When my son reached puberty I started to notice his underpants are wet with his ejaculation. I knew then that he has wet dreams".

It is quite obvious from the women's responses that they are more familiar with identifying their daughters' signs of puberty. It could be due to the fact that as women themselves they know well enough when to expect these signs, especially that one of the signs, "onset of menarche", is directly related to fertility which is the central essence of women's existence in their view. It was also obvious from the responses that mothers of boys notice only the signs that are seen by everybody, which indicates a relative sense of privacy and less physical intimacy between mothers and their sons.

\section{Menstruation}

Previous studies in Egypt have indicated that in rural areas girls menstruate between the ages of twelve and fifteen, with few menstruating prior to that 
age range and a few menstruating after. (Snowden et al. 1983). In our small sample only two of the respondents had their first cycle before they reached twelve, while the majority (31) menstruated between twelve and fourteen, and a few (8) menstruated at the older age of fifteen and beyond. Delay in onset of menarche beyond age fifteen causes alarm among rural families especially if the girls are not yet married.

Onset of menarche is an important "rite de passage" to womanhood in Egyptian culture. Once girls report their first menstruation they are instructed by their parents to refrain from talking to boys or playing with them. Some are asked to quit work in the fields and are confined to household chores, others are informed about chastity and virginity and its importance to their future life, but all of them (at least those who were not married before the onset of menarche) are congratulated and are told that they are now ready for marriage and motherhood.

The majority of our respondents (22) reported learning about menstruation only after they had had it, while the remaining nineteen knew about menstruation prior to its onset. Respondents who were not informed about menstruation described their experience as a distressing one, full of apprehension, panic and alarm. One of the older women said, "I was so scared, I thought I was dying."Another woman told us "When I saw the blood in my pants, I panicked and I did not want to tell anyone lest my family would think a man did something bad to me". On the other hand, the respondents who had been informed previously perceived of menstruation as a normal episode in a woman's life, and had no fear or complaint about its onset. Two respondents said that they were very happy and cheerful when they got their first cycle, "I was very happy to get my period because menstruation helps develop a woman's shape, she becomes more beautiful and is able to bear children and improve her status".

A substantial proportion of respondents mentioned that the source of information regarding the onset of menarche was the mother (18). Peer groups were next (12) in passing on such information, followed by close relatives such as sisters, aunts or neighbours (7). Four of the respondents were informed by their in-laws because they menstruated a few months after 
marriage. Very few respondents (6) reported feeling embarrassed when they first got their periods. On the contrary, the majority declared that they do not associate menstruation with modesty. One of the women told us, "I was already married when I had my first cycle, I had been introduced to "guema'a" (intercourse), and to the penis, why would menstruation embarrass me?".

The information relayed to girls about the menstrual cycle when it happened did not exceed the management of menstrual blood and the cleansing ritual after it is over. Zeinab who is now forty-three years old told us, "My mother told me to wear a piece of cloth (a rag) which I should change and wash once it gets wet. Nowadays, I hear women buy cotton from the pharmacy for this purpose". Another woman reported, "When I saw blood in my pants I ran to my mother-in-law who told me not to worry, and that this is my monthly period. She taught me to wear two pants so that I will not stain my clothes. She also told me to wash and cleanse my pants as quickly as possible because no one should see traces of this blood".

On probing further about the rituals related to the onset of menarche, we found out that most rituals that had previously existed in Egyptian culture (Khattab 1978) are no longer practiced. Only eight of our sample (older respondents) related to us some of the rituals they were asked to perform upon the onset of menarche. Some of these rituals were to ensure fertility such as hugging a "zir" which is a big clay water container. Since ancient Egyptian times water and soil have been the symbols of fertility. Another ritual had to do with good health, the duration of menstrual flow or pain during menstruation. To confine the menstrual period to three days, girls were asked to hug a palm tree and turn around it three times. Girls were also asked to poke their finger in a crack in the wall to minimize menstrual pain. The perception that hugging a tree after the onset of menstruation would bring good health was mentioned by only four older women. This indicates a noticeable change from past traditions and practices.

When women were asked about intercourse during menstruation, the large majority said that they refrain from intercourse while menstruating. The reason they gave was that it is harmful to the health of the man. Very few 
mentioned that intercourse during menstruation is prohibited by Islam. One woman asked whether it is true that Islam discusses menstruation and intercourse. She asked for the Qur'anic Verse which says that one should abstain from intercourse during menstruation, "They ask thee concerning women's courses. Say they are a hurt and a pollution so keep away from women in their courses, and their courses, and do not approach them until they are clean" (El Bakara S11, V. 247). The verse was given to the woman, and she reported that she would like to give it to her husband so that he would not demand sex while she is menstruating. Only one woman said that her husband was very demanding sexually and not even menstruation would stop him from approaching her. A young respondent relayed to the researcher that to stop her husband from sleeping with her while menstruating, she had to complain to his mother, who scolded him and asked him to abstain from pressuring his wife. Other women said that they often use menstruation as an excuse to turn down their husbands' demands for sex.

Although very few respondents alluded to the fact that, in Islam, intercourse is forbidden during menstruation, the large majority of women (38) abided by this doctrine. Cleansing after intercourse is another practice that all women observed regardless of whether they pray or not. Menstruating women have to take a bath to move from an unclean state (nagassa), to a state of cleanliness (tahara). The majority of women believe that they should wash with hot water and soap in order to be cleansed before they recite EI Shehadatein, "I Witness that there is only one God, and I Witness that Mohamed is the Messenger of God".

A number of taboos and behavioral restrictions associated with menstruation were cited by women, mostly related to traditional accounts related to passing the evil eye, (mushahra). Menstruating women are not supposed to visit newlyweds and postpartum women; nor are they supposed to work in the fields, particularly in planting certain vegetables (like eggplants). These traditional beliefs pass from one generation to the next through the socialization process and convey the meaning of "impurity" of women during menstruation. 
Menstruation is probably the first "rite de passage" which is perceived by most women as directly related to fertility and procreation and consequently to sexuality. Once girls menstruate they are considered ready for marriage and for intercourse. Hence their activities outside the home are restricted and their relations with the other sex are confined and controlled.

\section{Female Circumcision}

Female circumcision is another "rite de passage" or "life crisis" that Egyptian girls have to pass through before they reach womanhood. Most writers on the subject seem to agree on the definition of female circumcision, excision, or clitoridectomy. It is referred to in classical Arabic as "khafed", and the popular term used in Egypt is "tahara" (purification), (Assaad 1980). It denotes the partial or complete removal of the external female genitalia, varying from the removal of the prepuce of the clitoris only, to the full excision of the clitoris, the labia minora, and the labia majora. (Karim et al. 1965a; Meinardus 1967). In Egypt, the most commonly practiced circumcision is the first degree where the labia minora are removed and occasionally the tip of the clitoris, or in some cases the second degree, where the labia minora and a part of the clitoris are removed. In the third degree, the whole of the labia minora and the whole of the clitoris are removed, while in the fourth degree (Sudanese tahara) the labia minora and majora are completely removed together with the clitoris (Karim et al. 1965b).

There is no clear information that could help trace the origin of this practice in Egypt. It is difficult to ascertain whether it was originally an old African puberty "rite de passage" that was diffused to Egypt at one point in time, or a pharaonic survival that was adopted by the Egyptian culture and might have spread to other parts of Africa (Meinardus 1967). There is no historical evidence that female circumcision originated or even was practiced by Muslims in Arabia, where Islam originated, nor in the countries that adopted Islam first and were in close contact with Arabs from the African Peninsula before and after Islam. Female circumcision was never, and is not, practiced 
today in Saudi Arabia, the Gulf countries, Iraq, Iran, Syria, Lebanon, Jordan, Palestine, nor the North African countries other than Egypt. The only connection of the practice with Islam is a "Hadith" that Muslims in Egypt use to indicate that the practice is a "Sunna" of the Prophet (tradition) where Mohamed told a midwife to reduce and not remove when circumcising. The Hadith, unfortunately, is recited without a context which specifies whether the midwife was performing circumcision for a boy or a girl. Moreover, the Hadith does not specify the anatomical part to be reduced, whether it is a male or a female organ.

Circumcision for boys is known to be performed by midwives in some Muslim countries. Only in Egypt do we find very clear division of gender roles in performing circumcision, where midwives perform circumcision on girls and "health barbers" (traditional practitioners) perform it on boys.

Findings from the Giza Reproductive Morbidity Study indicated the present extent of the practice of female circumcision in rural Giza. The entire sample had been circumcised, even women who were originally from Cairo or other urban areas. The circumcision performed varied according to age. Most of the older women, thirty and over, had second degree circumcision, while most women under the age of thirty had first degree circumcision.

Women's knowledge and perception regarding circumcision (male and female), and the reasons for the practice, were investigated. Most women said that male circumcision is a cultural tradition which is practiced by everybody (15), or that male circumcision is a hygienic and cleansing practice (14). Eight respondents gave physiological reasons for circumcision, reporting that male circumcision is performed to enhance growth, facilitate urination, improve sexual relations (no obstruction to penis penetration) and smooth ejaculation. Only four women alluded to the "Islamic Sunna" which considers male circumcision as an obligation for all Muslim men. Female circumcision, on the other hand, was perceived as a hygienic and beautifying practice by eighteen women who claimed that beautifying means removing the part that would otherwise make them look like men. It was also perceived as a tradition by ten women, as a means for restraining sexual desire for girls by eight, as an Islamic Sunna by three, and 
as better for marriage relations by two. Attenuation of sexual desire was mentioned exclusively for girls. Only four respondents added a physiological reason for female circumcision, mentioning that it may speed up puberty among girls.

The operation, for most women, was performed by the traditional midwife between the ages of six to twelve with the majority being circumcised before they reached ten. Women reported that boys, on the other hand, are circumcised before they reach the age of three, the majority being circumcised during the first six months of their lives starting from the first week. The large majority reported have circumcised their daughters, or intended to do so. When asked who should perform the operation for their children some said that female circumcision should remain among the roles of the traditional midwife (25), while sixteen respondents said they may resort to physicians because it is more hygienic and less painful for girls as physicians use local anesthesia. With regard to male circumcision some women felt that the "health barber" could perform the operation (22), while nineteen believed the operation should be performed by a physician.

Although many respondents said that female circumcision is a tradition or a practice that all girls have to go through, very few reported having been informed about the operation before it was performed. The few women who were informed about it, were only notified either a few days before or on the same day the "daya" was called. They were told by their mothers (5), or by close relatives (5), "You are a grown-up now, you should bear responsibility, hence you must be circumcised". In other cases they were told bluntly, "You will be circumcised, today or tomorrow". When respondents were asked to elaborate further on their feelings and attitudes upon receiving the news that they will be circumcised, the majority, (fourteen out of twenty-four) reported to feel very happy. "A girl is happy after circumcision because she feels she has reached adulthood". "Once you are circumcised, other children will not tease you about having a 'zubr' (penis)". Fatma related to us what she did the day she was circumcised, "I went out to the alley and lifted up my skirt and proudly showed my friends that I was circumcised". On the other hand, seven respondents reported they 
were afraid when they were told that they will be circumcised. One said that she can still remember the pain and fear of the blood, and that she does not want to circumcise her daughter, because of the fear of the operation. Another one said that when she was eight, her mother insisted on the operation, "I was afraid when I saw the blood and was in pain for a few days afterwards because my mother used to put me in a basin of hot water and apply some antiseptic to the wound". Three reported to be passive, neither happy nor afraid.

As women reported, rituals and ceremonies surrounding circumcision are somewhat different for boys and girls. For boys, the festivities reported comprise inviting relatives and friends for a meal accompanied by singing and dancing (11), or it could be limited to cooking a nice meal for the circumcised boy or visiting holy shrines (2). On the other hand, the poorer respondents may not celebrate the event and some referred to a saying, "Celebrate a marriage, but not a circumcision". Female circumcision was reported as a much quieter event. Some women indicated that a chicken is cooked with some rice, or that sweet drinks are given to the circumcised girl to compensate for the blood loss she experiences (19). Others said that they just disregard the event (14). Only one woman said that they do celebrate the circumcision for girls, and another one said that they buy the girl a new dress for the occasion. This difference in rituals and ceremonies surrounding circumcision of boys and girls is one of the practices taking place from early childhood that indicates gender differentiation and preference for male offspring. The early gender differentiation reinforces women's feeling of subordination. Several respondents in talking about the lack of celebration for female circumcision mentioned a proverb which states that girls have broken wings, meaning that girls are crippled, hence, subordinate and dependent like a bird with broken wings.

Women were also asked if they believed, or felt, that circumcision has influenced their enjoyment of the sexual act. Most respondents reported that they feel circumcision has no impact on their sexual relations with their husbands. One of the respondents said, "A man always knows how to excite a woman, I don't believe that there is a frigid woman. A woman is a 
woman". "Circumcision has nothing to do with mutual pleasure, when a woman wants to please and be pleased, she can do it, and when she doesn't want to do it, she wouldn't". "Orgasm, does not come from this part, it comes from the uterus. When the man enters the woman she feels all the pleasure". On the other hand, many women (fifteen out of twenty-seven) believed that lack of female circumcision is an obstacle that hinders intercourse and displeases a man. They expressed their fear that men would divorce their wives if they are not circumcised.

From the focus group meetings and women's responses during interviews, it thus became apparent that women at the village level, do not perceive of female circumcision as a bodily mutilation, nor even an act of violence against them. On the contrary, they believe that the practice is performed for the benefit of women as it accentuates the biological difference between the sexes, "We do not want to look like a man with a protruding organ". Women's comments also indicate that female circumcision reinforces their identity with the female sex. Responses from women have clearly shown that female circumcision is perceived as a "rite de passage" like menstruation, marriage and childbirth because it moves women from one status to another in their life-cycle. In fact, several comments by women who participated in the focus group meetings indicated that they resented the comments by the anthropologist concerning the disadvantages of female circumcision. The women objected to her comment that the practice is more harmful than helpful and that it has no religious grounds justifying its performance.

As was obvious from women's perception, female circumcision in their opinion, is related to sexuality and gender; women reported that female circumcision is practiced to beautify girls by removing any protrusion in their genitals so that they look different from men. At the same time other women stated that female circumcision is to beautify girls in order to please men, while others did mention the restraining of sexual desire. Most of the comments, whether direct or indirect, were always alluding to sexuality, gender relations and to sexual pleasure. 


\section{Perception and Attitude towards Vrginity}

Virginity holds a central place in the culture of sexuality of Egyptian peasants (Abou Zeid 1965). The hymen is referred to as "wish el bent" meaning "the face of a girl". The use of the analogy with the face, which gives a girl her identity, denotes the importance of virginity for girls. A girl without a face has no identity or place in her community. Egyptian peasant girls are taught at a very early age the importance of their virginity. They are warned not to allow any man to touch their genitals, and are advised not to sit on or ride anything hard that might injure or gash their hymen. Usually blood from this area calls for fear and concern. One of the respondents reported that her father used to tell her often that he will use his sharp knife against her and whoever comes close to her genitals. She said, "I used to be very careful riding the camel whenever I transported hay from the field to our home and I was quite sure I never came close to a man. Yet despite all that I was so horrified and scared when I got my first period, thinking that a man could have done this to me while I was sleeping. I did not tell anyone so that my father would not use his sharp knife on me". When respondents were asked what does "wish el bent" (hymen) mean to you, most (16) said the blood on the white handkerchiefs on the wedding night, while eight said it is the membrane closing the orifice of the vagina and twelve said it is the honour of a girl. This latter group were of the older generation.

Although virginity still holds an important place in Egyptian peasants' perceptions of sexuality, yet the attitude and disposition of the youth, the educated and the urbanized is more relaxed now than it used to be far back in the 60 's or 50's with regards to exposing girls' virginity to the whole community. A growing number of young educated men and women prefer to consummate marriage the "Egyptian urban way" (as they refer to it), meaning the young couple chooses to be alone during the wedding night, instead of the "traditional ceremony" in which intercourse or the use of the finger to cut the hymen has to be performed in the presence of a daya and relatives.

The respondents were then asked whether they thought some girls do have pre-marital relations. Five of the respondents denied that girls could have 
any pre-marital relations and one respondent said she didn't know. The large majority (35), on the other hand, declared that some girls nowadays could be exposed to pre-marital relations. This perception, in most cases, referred to urban youth rather than rural, as respondents always referred to Cairo where anything could happen. An older respondent told us, "What do you expect when girls walk with boys, study with boys and even go on picnics with boys. In the past only girls that worked in the fields had any contact with boys, the rest were kept at home once they came of age". When respondents were asked to relate one or two incidents of pre-marital relations in their community the same few stories were repeated by several women. Two of these stories had become known nationwide because the incident was an incest relation where the brother killed his sister when she told on him. Of the thirty-five respondents who attested that pre-marital relations do occur, the majority (20) believed that pre-marital relations probably exist but are concealed (surgical repair of the hymen) before girls get married. On the other hand, fourteen of the respondents said pre-marital relations could never be rectified because once the hymen is destroyed, the damage is done and there is no way it could be made right. One respondent did not comment on this issue.

Women who believed the situation could be rectified (20) were further asked about who could correct such a situation. Thirteen mentioned the role played by the traditional midwife who is usually approached by close relatives (mother, maternal aunt or older sister). The traditional midwife is usually prepared with the blood of a pigeon in a small bottle. The handkerchief is then smeared with the blood during the deflowering process. Four more women reported mothers and relatives to be able to cover up (most probably through the midwife). Two participants mentioned that in more recent times, parents or adults who are faced with such a dilemma resort to surgeons who are able to repair the hymen by making a few stitches. Only one participant mentioned the use of indigenous methods or remedies. Despite the occurrence of such incidents, from time to time, pre-marital sex among girls is still considered a deviation from the norm and is neither accepted by the family nor the society at large. 


\section{Marriage and Initlation of Sex Relations}

Deflowering is defined as the rupturing of the hymen (of a virgin) by sexual intercourse. In Egyptian rural customs and traditions, deflowering is mostly done by hand and not through regular intercourse. In fact Islam rejects any intercourse other than by the male organ and not before a period of foreplay as was mentioned in many Hadiths by the prophet Mohamed (Sabek 1990; Mahmoud 1988). The hymen is torn by inserting the forefinger enfolded in a white handkerchief into the outer vagina of the bride pushing hard until the hymen is ripped off and the blood oozes out on the handkerchief. Deflowering takes place in the groom's home which is in most cases a room in his parents' house. Relatives, neighbours and friends are invited by both families to attend the celebration. During the few minutes when the deflowering takes place the guests wait quietly outside the house until one of the women assisting in the deflowering (usually a paternal or a maternal aunt) comes out with the handkerchief soaked with the blood evoked by tearing the hymen of the bride. Once the handkerchief is shown cries of joy (zaghareet) are heard everywhere and the singing and dancing of female friends and relatives starts.

Reports of women on the deflowering in the study community were as follows: the deflowering was usually performed by the husband with the help of the traditional midwife "daya" (15); some husbands preferred to do it themselves without outside help, yet it had to be done in the presence of "dayas" and relatives (10); in other families the job was left entirely for the "daya" or close relatives (7). Of our small sample, nine of the couples chose to marry the "Egyptian Way", referring to urban practices of deflowering by sexual intercourse. These more modern rural couples, nonetheless, have to prove and announce the virginity of the bride by showing the handkerchief to their families at a later date and in a more private manner.

Women were asked about their wedding night and whether they were informed of what takes place during the deflowering of the bride. The majority (23) of women claimed not to have understood exactly what deflowering entailed. These were mostly the women who had married at a very young age. The remaining sixteen said they were informed either by 
friends, parents or close relatives such as sisters or aunts. Only one participant said her husband was the one to inform her after marriage and teach her all she knows about sex. She related this to his being educated. When they were asked further to elaborate on their feelings during their wedding night, again the majority (23) said that they were not only disturbed and agitated, but were fearful of the whole episode. Eleven respondents said that they did not think about it because it was such an ordinary matter, while seven of the women reported to be happy because they would prove their virginity and chastity to everybody in the village and in this way they would honour their families

Undoubtedly, the deflowering process was a traumatic experience to the majority of the respondents (22) who reported experiencing anxiety and fear prior to the act of deflowering and pain and panic during the act and after. A few women said that they had fainted during their wedding night through fear and exhaustion. Nine women reported that their husband slept with them immediately after the deflowering which was quite painful, with four indicating to have had intercourse several times after deflowering despite the pain and the discomfort they had felt.

Deflowering was reported as a painful experience, especially for those who were not informed and did not know what to expect. Zeinab told us, "When I entered the bedroom, the traditional midwife (daya) was already there with my paternal aunt. They gave my groom a white handkerchief and he put his hand inside me, I was abhorred and when I felt his finger pushing at my hymen I screamed. He was so scared, he ran out of the room. When he came back to try again, he put his hand between my legs and I felt like a shovel was being pushed inside me. The Daya then finished the job by gouging my inside until the handkerchief was soaked with blood. When everybody left, he slept three times with me. I felt awful, it was more than painful ".

When we asked the women what marriage meant to them or how they perceived of marriage when they were told they were getting married the majority responded by saying, "Household work at the new home". Thus marriage meant moving from one household to another to carry out the same household chores. Their family of orientation usually prepares them to carry 
out these chores in their new family of procreation. This new family of procreation is'usually composed of the father and mother-in-law, and unmarried siblings. Sometimes married brothers also share the same household arrangements, hence, the daughters-in-law are expected to carry out the burden of work at home and in the field depending on time and need. The mother-in-law orchestrates the various responsibilities according to seniority and expertise. Older daughters-in-law are asked to do jobs such as milking cows, cooking etc. Other jobs which are of lower status such as washing, cleaning the house or helping in the fields are in most cases delegated to younger daughters-in-law who are usually the newly-weds. Several respondents who married at a young age (12-13) told us that they never knew that sexual relations were included. Consequently the younger brides thought their husbands were trying to assault them sexually when they tried to sleep with them after the deflowering. Fatma, a 12 year-old bride, told her husband on her wedding night, "Do not do these bad things to me, my mother would kill me". Other respondents said that they have always heard that the wedding night is the best night of one's life. They have their own rooms, they have new clothes, and new jewelry, not to mention that they become the center of attraction during that celebration.

The deflowering tradition is absolutely necessary for girls who work in the fields. These girls have to prove their virginity to the community because working in the fields exposes them to contact with the other sex in settings which are remote. Sawsan told us, "When the mid-wife and my groom took my face (broke the hymen) and sent the handkerchief out, I heard the cry of joy "zaghrouta" of my family and all the pain and agony that I felt were gone. I was delighted I honoured them by being a virgin, and at the same time I took revenge on my aunt who used to criticize me for working in the fields".

Deflowering in the Egyptian peasant culture is a practice that legitimizes sexual activity for the married couple, that is, it gives a legal license to the couple to practice sexual intercourse. Once deflowering is over, the couple's sexual relation is accepted and taken for granted and the subject becomes less private, and the couple's sexual behavior and its outcome becomes the 
concern of others (Quite often we find women joking among themselves about the sexual behavior of the newly-weds). At the same time family members, friends and neighbours start asking about the signs of pregnancy and urge the couple to start a family.

\section{Women's Perception of Body Organs}

As Bourquia (1990) puts it, "The way a woman's body is perceived in society is determined by the social structure of such society". The social structure establishes the status of individuals and regulates relationships between men and women, as well as their perception of themselves and of each other. In our case in Giza, the perceptions of village women about themselves and their bodies reflected the way the society envisions their status and the roles they play within the family and within the community at large. The assumption "that woman was created not only from man but also for man, which makes her existence instrumental and not of fundamental importance" (Hassan 1994), prevails to a considerable degree in the village setting. This belief was best exemplified in the responses of our women to the question concerning their self-image and their perception of their bodies. Some of the comments were, "A woman without a healthy body is useless to men", "A woman's body is there to please a man", "Women are there to raise children and carry out chores for husband and family".

The culture perceives of women as the subordinate sex, but never as the weaker sex because there is a lot of physical demand on the woman as a wife, and a mother, working in the household as well as in the fields. From early childhood and during the socialization process girls are taught the attributes of a strong body that can carry a heavy burden of work, and that can endure pain and discomfort without any complaints. From the age of five and sometimes even less, girls in the villages are burdened with the responsibility of taking care of their younger siblings, carrying water to the house, and washing utensils (Khattab et al. 1987). When they move as young brides to live with their in-laws, they are urged to be industrious and to demonstrate their physical fitness by carrying out all chores assigned to them by the more senior women and men in the household in a submissive 
manner. They are advised not to complain when they are tired or unwell,.. "Men do not like disabled women" (Khattab 1992).

As women move in their life cycle, however, their status improves. The status of a mother in a nuclear family and of a mother-in-law in an extended family is relatively high, and it becomes even higher in the absence of the male head of household (either through death or work as migrant labour). Therefore the eldest woman in the household, besides being the dominant figure who holds responsibility for the domestic running of the house and the division of labour among women, begins to take part in all decisions concerning the household. Furthermore, the change in the status of a woman from mother to mother-in-law increases her self-image. Even when a woman's eldest son becomes the head of the household, he must consult her and report to her first before taking any final decision. In other words, the mother has the power to share decision-making with her sons, and in some cases her voice is the strongest.

Women respondents were asked to name the various organs of their body and to describe the function of the various systems. Their answers indicated that the majority of respondents perceive of their abdomen as a cavity where the organs float together and interact with each other but not within systems. A few women, on the other hand, believed that individual organs have separate functions which do not interact with other organs. Moreover, one respondent who had university education described functions of body organs within systems, as circulatory, respiratory and so on. Four other respondents mentioned almost all organs without specifying most of the functions. The large majority (29), nevertheless, could name only a few body organs, and mentioned symbolic functions for them which reflect the cultural beliefs, attitudes and perceptions of the community.

One of the younger respondents told us, "My heart beats wildly when my husband talks fondly to me; it also beats when my mother-in-law scolds me". Other comments indicating the relation of the biological with the cultural were, "The heart has everything, it beats when a man touches a woman"; or, "My heart directs me who to love and who to hate"; " The eye sees the beautiful and the ugly and it differentiates between the two"; "The 
brain enlightens us to know right from wrong and directs us".

When we looked at the order in which body organs were mentioned by the women, the heart came first (26), then the stomach (21), then the liver (18), and then the kidney (16). The uterus (beit el weld) and the ovaries (mabayed) were mentioned by only ten women in response to a specific question on body organs. Other organs such as the eyes and the brain were mentioned by five and six respondents, respectively. It is interesting to note that respondents who themselves had a certain health problem, or who had a close relative with a problem, mentioned that organ first. The woman who had an eye disease mentioned the eye first, and the respondent whose husband suffered from kidney failure, mentioned the kidney first.

\section{Knowledge of Physiology of Reproduction}

Women were further asked more specific questions about the physiology of reproduction and how conception takes place. Most women mentioned that the uterus is the place where conception takes place. It is referred to in colloquial Arabic as "beit el weld" which means "house of offspring". Although the ovaries were mentioned by some women, yet only a few knew of their function, nor were the ovum (bayda) and the fallopian tubes mentioned by most respondents. One respondent said, "I know about ovaries, women have ovaries, but I do not know what they do". Another woman reported that, "The uterus is there and the ovaries are there, each has its own work but their work is not related". It was noticeable, however, that women who have had fertility problems, whether primary or secondary and regardless of their education and status, were more aware of the physiology of reproduction and the function of each organ. Undoubtedly, the increased knowledge of these women is due to their exposure to some medical facts while seeking treatment in medical settings. Women knew about and perceived of the penis and the sperm as essential organs for conception, because it is information exchanged among peer groups. Yet the mechanism of conception was unknown to most women, except to the few who had preparatory or secondary education where information was given to them in 
biology classes. However, most respondents mentioned intercourse as a basic necessity for conception.

A question on how and where conception takes place was asked in order to evaluate women's knowledge about the biological aspect of conception, to determine what they know about the ovum, the tubes, and sperm. The answers varied from those who knew nothing about the mechanisms of conception, to those describing the meeting of the ovum and sperm in the uterus. The majority, however, (30 out of 41) said that conception occurs with intercourse without mentioning sperm or ovum. Some women (13) alluded to the analogy that women are like.. "the earth, where men throw their seeds which in time get fertilized in a woman's house of offspring". Two of the respondents associated conception with menstruation. A statement such as, "When my period is missing I know I am pregnant", is quite common among village women. It was quite evident that most village women do not really understand the process of conception: what organs are involved, the function of these organs, and how contraception works. Moreover, these findings could, in turn, explain the wrong use of contraceptive methods such as the pill among peasant women in Egypt. When women are ignorant of the biological aspect of conception they tend to misuse contraceptives, assuming that taking the pill after intercourse would be sufficient.

\section{Talking about Sexual Activity}

As was mentioned earlier women in the village did not demonstrate any inhibitions in discussing sexuality with the researchers. Although the researchers tried to conduct the interview in privacy, some women did not find it embarrassing or uncomfortable to proceed with the discussion when a neighbour, a relative, or an in-law came into the room; only a few women insisted on talking in the privacy of their room. It should not be taken that the latter group are necessarily more modest than the others; it was also a way of showing that they were privileged because they were selected from the rest of the household to participate in this project, and that they are close 
friends to distinguished visitors like the research team.

When women were asked whether they discuss sexuality, especially intercourse, with anyone, the majority replied that they discuss it with their husbands (30) while the remaining respondents reported that they discuss these issues with friends, relatives or neighbours. Only one respondent said that in case of discomfort during intercourse she would talk to her mother. To probe further, we asked the women what they talk about when they discuss sexuality with their husbands. From their responses, we gathered that they discuss extra-marital relations among men, especially those who work abroad, and they talk about female sex workers, where and how men get to know them. They talk about sexuality and sex behavior in other Arab countries in which men work as migrant labourers. One husband went as far as describing to his wife his sexual practices with other women from Sharee El Haram (red light district area in greater Cairo).

Mona said, "My husband once told me that when he had a mistress while we were married and had our three children, he had anal and oral sex with her. I do not know why he tells me all this. Does he want me to be jealous, or does he want to encourage me to indulge in oral and anal sex". The lab test undertaken as part of the larger Giza Morbidity Study had indicated that this respondent suffered from Chlamydia. She was transferred for further tests. She was informed of the infection and was told that it is sexually transmitted. The husband expressed his willingness to take any medication the physician prescribed. Medication was sent to both of them. Mona told us in a later visit that her husband was so scared that he promised not to continue with his promiscuous habits.

Women also reported that they discuss sexuality among themselves. In fact, the researchers frequently observed village women talking and joking about intercourse among themselves. Statements such as, "Look at her bright face and her red cheeks, she must have had it last night"; "Her hair is still wet, she had a good bath at dawn", insinuating that she must have had intercourse early that morning.

Respondents said that women nowadays discuss among each other pornographic films imported from India or made in Egypt. The owner of the 
village coffee shop (the husband of one of our sample) has installed a television and a video in his shop, where men can watch pornographic films after $11 \mathrm{pm}$. When he heard that his wife and her neighbours told us, he came rushing to the researchers the following day to say he would not show the films again and that he repented that he ever had. We believe that he was afraid that the research team would report him to the police because showing pornographic films is an illegal act. On the other hand, other women in our sample denied that they ever saw such films or discuss such topics with people other than their husbands.

\section{Libido}

Most of our respondents perceive of the sexual act as a relationship between husband and wife, in which the husband reveals his love by being tender and affectionate during intercourse and the wife reciprocates similar feelings. The majority of women (27) reported to feel and enjoy their husband's love and affection during sex, while twelve said they feel this closeness occasionally, depending on their mood. The remaining two women reported that they rarely feel love or affection during intercourse because their husbands are either brutal or not affectionate.

In response to questions about the experience and frequency of orgasm, the large majority of respondents (39) said they experience orgasm during intercourse. Of these, twenty-seven reported to enjoy sex almost everytime, and the twelve said that they experience orgasm occasionally and not every time. When we probed further as to why and when some women do not enjoy sex, women said this happened because women are sometimes obliged to sleep with their husbands even when they are not in the mood for it, either because they are not feeling well, or are overworked, or are worried about someone. In such instances women respond to their husband's demand because they feel it is their duty to do so, even if they are too tired to enjoy it. It was interesting to hear the comments of an older woman who said, "Village women recognize and identify a considerate man from his sexual behavior with his wife. A good man is viewed as a man who does 
not pressure his wife for sex when he notices that she is over-worked or not well".

When we asked women about the first time that they had enjoyed sex or felt orgasmic, fifteen said during the first week of marriage, while thirteen said during the first three months of marriage once they got used to their husbands, and eight said they did not enjoy sex except after the birth of their first child. One respondent reported to start enjoying intercourse after the onset of her menarche. This woman married at a very young age. She menstruated several months after marriage during which time she had had regular intercourse with her husband.

Of all our respondents, and the other women with whom we discussed this issue during focus group discussions, only two women reported not to enjoy sex at all, nor to have ever reached orgasm. When we tried to probe more about the background of these two women, we found that both women were unhappily married. Mounira who is 33 years old is living in a composite family with her widowed brother-in-law and his young daughter. She helps her sick husband in the fields and carries out most of the household chores for the two families. She informed the researcher that harsh memories of her wedding night still persist in her mind, "After my wedding night where the midwife and my husband poked their fingers in my inside, my husband slept with me several times that evening and every time we had intercourse I bled more. A few days later I swelled below, my parents took me to the doctor who gave me ointment to apply there and another medication to wash with. For several days I would not let my husband come close to me, I was so scared of him and of what he would do to me. I avoided him until my father and my uncle came here and talked me into allowing my husband to sleep with me. After that I got used to it. This is my lot in life what can I do ?". When she was asked whether she discusses this issue with anyone, she said, "I hear women talking about having orgasms and when I tell them I never felt it, they laugh and tell me the midwife must have removed your hot vein when she circumcised you". By "hot vein" the respondent meant the sensitive area in the clitoris which gives the most pleasure.

The other case is Laila who is around 40 years old and has seven children, 
three of whom are married. She too has bad memories of her wedding night: "After the deflowering by the midwife and my husband, he slept with me against my will. He was aggressive. He shouted at me and hit me and forced me to submit to his demands". Laila perceives of herself as a utensil where her husband can throw his sperm whenever he wants to release his tension.

In answer to the question, "Do you think your husband feels whether you reached orgasm or not?" the large majority (34) of those who responded to this question affirmed that the husbands are aware when their wives reach or do not reach orgasm. "My husband always asks me whether I came or not, we always reach orgasm together". "If I climax before him he asks me why are you in a hurry". "My husband is intelligent, he knows and feels when I reach orgasm, he sometimes controls ejaculation until I reach climax. Other times he waits until we reach orgasm together which is better for him".

The frequency of intercourse was discussed freely with the women. None of them demonstrated any inhibitions in discussing that issue. On the contrary, they volunteered side information concerning relatives and friends. One of the young respondents, who is living in an extended family, told us proudly that the men in her husband's family are known for their virility. She reported that her father-in-law, who is over sixty, has a bath every afternoon, (a bath refers to the cleansing bath that is taken after intercourse).

When respondents were asked how often they have intercourse, sixteen of them declared that they have intercourse daily or more than four times a week, thirteen reported to have sex twice a week, and eight reported to have sex once a week. Four women did not specify how often they have intercourse, but said, "We leave it to circumstances".

The question of frequency of intercourse was further analyzed by the ages of wife and husband. Yet in both cases, age did not appear to have an impact on the frequency of intercourse because the distribution of the responses was almost equal among all age groups. Age groups were divided for men as follows: under thirty, between thirty-one to forty and between forty-one to fifty; and for women: under twenty, from twenty to thirty, from thirty-one to 
forty and from forty-one to fifty. When the same question was analyzed with husbands' work (agricultural labour, employee, or manual labour), the frequency of intercourse was shown to be slightly lower for the manual labour category (not statistically significant). Moreover, the three women who mentioned that frequency of intercourse depended on circumstances were married to manual labourers. This could be explained by the fact that manual labourers have longer and uncertain working hours, unlike peasants who return home at sunset.

\section{Wives' Perception of Husbands' Right to Sex}

When we probed about women's perception on husbands' demand for sex and the usual response of wives to these demands, the majority of respondents (24) stated that they would never, under any circumstance, refuse their husband. On the other hand, eight said they do occasionally refuse sex and nine said they can refuse sex if they are tired or sick. Some village women use indirect ways to avoid sleeping with their husbands. Some pretend to be sick or menstruating, others wear "uninviting" clothes (dress that covers most of body), or refrain from taking a bath or changing a soiled "galabia" dress after finishing household chores. A few women told us that they resort to sleeping in another room with their children whenever they want to avoid sex.

We probed further to find out the perception of women concerning women's rights and obligations regarding sexuality within marriage. A substantial number of respondents (16) affirmed that it is a husband's right bestowed by God to have intercourse with his wife whenever he needs it and that she is obliged to satisfy this need. No quotation could be found from the Holy Book (Qur'an) to support this belief, but a Hadith was found mentioned by El Bokhary cited by Ibn Houraira that Prophet Mohamed said, "When a man calls his wife to bed and she refuses, he will sleep in a state of anger, angels will curse her until she wakes up". Unfortunately, the Hadith was quoted without mentioning the context in which the question was asked because that would have given us the true stand of Islam on that issue. Five of the 
women claimed that satisfying the husband's sexual need does not only please him, but it pleases her too because she also feels wanted and desired.

Only three women said that they submit to their husband's sexual claims in fear of what he might do. Fatma told us, "My husband has a bad temper, if I refuse him he might hit me with anything, hence, to avoid problems at home, I submit unwillingly to his demands". A few other women mentioned that the fear of loosing their husbands to another woman compels them to satisfy all their husband's sex needs whether they want to or not.

This feeling of obligation towards the husband is developed during the socialization process and especially when young girls get engaged and are being prepared for marriage. They are told by their mothers and other family members how important it is to respond to their husband's demands and that it is her duty to fulfill his needs whenever he asks them. Nobody explains to them what these needs are. Hence, many of the women, especially those who married at a younger age, perceived of these needs as tending to his daily chores such as washing his clothes, preparing his food, and waiting on him while he is at home.

Sahar said, "My paternal aunt told me everything; how to sleep with my husband, what I should do and how I should wash after each intercourse, and that I should hide the cloth with which I wipe myself because nobody should lay eyes on it. She told me that I should always be submissive to my husband's demands". Only one respondent said, "I can tell my husband I do not feel like having sex today. He is very understanding, he would never pressure me to have sex against my will".

Respondents were also asked about their perception regarding women's role during the sexual act. The large majority (33) said that women are equal partners and that they should participate during the act by moving, talking, or demonstrating enjoyment. However, twenty respondents believed that women should never start the foreplay and that men should always be the initiators of the sex act. The other half, on the other hand, felt that part of their role is to excite and entice a man for sex. They all believe, nevertheless, that their approach should always be discreet because it is not 
nice for a woman to show her sex desires, or to be refused. Some women declared a fear that "men might use this information against women in time of anger".

Most women mentioned various discreet ways of insinuating their desire for love-making. The large majority said that they do wash and change clothes in preparation for their husbands' return home. A few other women said that they use endearing words and an affectionate touch every now and then to entice their husbands. "My husband tells me silly things, like (Every woman sometimes feels a desire to have sex, you never ask me). It is true I never say it but I show it to him in a loving eye or an affectionate touch". The two more vocal women told us they do not mind to ask for sex openly. One of them said, "Sometimes I tell my husband, man! don't you feel like having a bath?". These two women were around thirty years old, were illiterate, and had been married for an average of sixteen years.

Women seem to conceal their desire for sex because they feel it gives them a certain power over their husbands and not because they are subordinate to them. Zeinab told the researcher, "A woman should never show her desire for sex. A woman has her dignity and her dignity should be above all. She must play hard to get, so that her husband would always desire her". Another respondent advised one of the researchers, "Do not ever ask your husband for sex, he turns into an arrogant, haughty man who would later take you for granted".

The question concerning the reaction of husbands to wives' refusal to have sex drew a range of responses. Fifteen of the women said that their husbands accept willingly their excuses not to have sex, while six said that their husbands accept occasionally but not all the time, and nine said that their husbands resent being turned down and in some cases become violent hitting or cursing them. "My husband is so violent, I could never tell him no. I let him do whatever he wants. I feel nothing". "He has always been harsh, he sleeps with me against my will, my neighbour could always tell when he sleeps with me because of the scratches and bruises on my face". Four respondents perceived of women's role during the sex act as a passive one, they claimed that women should be recipients only, especially those who 
were nicely brought up (did not go around which means never had premarital or extra-marital relations).

\section{Attitude to Sex Practices}

Women's knowledge of, attitude to, and practices of various sex positions were also investigated. It was found that more than half of the women knew of various positions for intercourse. Twenty women reported to know two or three positions for intercourse, yet only eight of them stated that they actually practice different positions. The remaining respondents (twentyone) relayed that they knew only one position which they referred to as the normal or natural position. The position they identified as normal (woman down, man up is perceived and rationalized by religious and gender arguments, whereby this position denotes the power of a man bestowed upon him by God and therefore other positions would be "haram" (prohibited). A biological explanation was also used by the women to sustain this cultural belief and that is that, if other positions are used (the man is not on top), the offspring will be born cross-eyed.

The other positions mentioned were: woman up/man down or side position ("the woman lies on her side and the man approaches her from the back", not anal). When the eight women were asked further to elaborate on why they practice various sex positions during intercourse, four respondents said they indulged in various positions upon their husbands' request, while the other four said they seek different positions themselves to increase pleasurable sensations, "I like to be on top, this way I do enjoy sex more because I control the position that gives me more pleasure". On the other hand, one respondent said she would not use except the normal position, saying that.. "the eye can never be above the eyebrows".

\section{Extra-Marital Relations}

Extra-marital relations was another subject discussed with the women. Although the subject was thought to be somewhat sensitive, the discussions 
were conducted in a very friendly atmosphere loaded with jokes. The large majority of interviewed women (39) responded in the affirmative when they were asked whether some men do indulge in extra-marital relations. Several women related a proverb which reads as follows, "Men are like dogs, you show them a leg (a bone), they come running. You yell at them, you frighten them away". It is interesting to note that similar examples were mentioned by women in Yemen (Myntti 1988) and in Haiti (Zalduondo 1993). This does not mean, however, that peasant women believe that a high percentage of men do indulge in extra-marital relations, but that men are capable of such behavior whenever encouraged. One of our respondents said, "Do you believe that a man can stay away from his wife for a year without comforting himself" (releasing his sexual urges). Another respondent retorted jokingly, "A woman who trusts men is a woman who trusts water in a colander".

Women gave several reasons why men would be involved in extra-marital sex. Seventeen believed that some men are promiscuous by nature, while eighteen believed that men seek sex outside their home whenever they are not satisfied or not happy at home, and four believed that men have extra-marital relations because they are seduced by other women.

Women were also asked whether they believed women also have extra-marital relations. Again the large majority (36) stated that some women do have extra-marital relations and are capable of seducing married or unmarried men. However, when they were asked to give an approximate number of women they knew that have extra-marital relations, most of them could not mention a figure. A few respondents said that they heard of one or two women who are visited by men at odd hours. They said, "My husband does not like me to talk to that woman or walk down her street. Women always talk about her. Most of them avoid her in fear she'll seduce their husbands".

When asked why women would seek extra-marital relations, the responses varied a great deal. Eleven respondents believed that women seek extramarital sex whenever the husband is not satisfying them sexually, or emotionally. Twelve believed that only women who are basically 
promiscuous would be involved in extra-marital relations or are easily tempted by men. One of the respondents commented that, "Some women cannot resist the temptation. Some men give a woman a certain look or a certain touch when shaking her hand and if she smiles, they would ask for more". "One of my husband's friends tried that with me when my husband got married to that other woman. I told him I am not like those women. Keep away". Nine of the respondents believed that women who are in need of money or are in need of sex while their husbands are away are tempted by the proposition of any man. These women did not specify cases and only one respondent said that a widow and a divorced woman are known to seek sex relations. (This comment would explain why divorced or widowed women were reluctant to have the medical gynecological exam in the Giza Reproductive Morbidity Study, lest people would insinuate that because these women have gynecological problems they must have had illegal sex). Meanwhile several women told us that the moment their husbands leave for Libya they go to the health center to remove the IUD, "When my husband left last week, my mother-in-law told me to go to the family planning clinic to remove the IUD until my husband comes back". It was quite evident from the responses and the discussions that women believe that men are more inclined to have extra-marital relations.

The cultural beliefs surrounding male sexuality suggest that men have more sexual urges than women. This is undoubtedly reinforced by the fact that men are allowed to marry more than one woman at a time. In addition, civil laws do not penalize male adultery on the same basis as female adultery. This collective conscious belief, among men and women, turns after a while into an unconscious fear on the part of wives of loosing their status in the household. This fear may emerge in the form of jealousy or suspicion. Except for three wives, who declared that they know when their husbands cheat on them, the majority of respondents could not tell. It is interesting to note here, that of the forty-three women in the sexuality study, we had only one polygamous marriage, where the two wives share the same household. Our respondent was the first wife. She reported to the researcher that her husband married a second wife because he needed an additional working 
hand in the fields. She claims that the husband does not love the second wife, because he is never sexually satisfied or happy whenever he visits her or spends the night with her. She characterizes the second wife as being filthy and sulky. She also said that her husband prefers to sleep with her, hence she uses this sexual power to tease or punish him whenever she is angry at him. She tells him, "Go to your unpleasant wife, I don't want you in my room".

\section{Homosexuality}

Respondents' knowledge of and attitude about homosexuality was investigated. It is important to note here that homosexuality in classical Arabic is referred to as "louwate" which is derived from "louks' people" as mentioned by the Qur'an. The term "abnormal sex" is the common term used in most Arabic-speaking countries. When women respond to this question they will mention any form of sex they perceive as abnormal.

The researchers found out that this question was one of the most sensitive subjects they had to discuss, and eight women did not want even to discuss it. Only twelve of the respondents reported that they knew of homosexuality. They knew that the relationship existed and had heard of some who practiced it. Some believe that men resort to sex with other men when women are not around, especially when they work abroad for a long time. One woman said, "I discovered that my husband is a homosexual, I saw him with another man one day when I took his lunch for him. The other man told me, Your husband bought me with a packet of cigarettes".

Women refer to homosexuality with disgust and lack of respect. The term "khawal" (homo) is one of the most insulting terms that can be used. Although homosexuality is unacceptable religiously and socially, yet in most cases it is tolerated. Most of the men referred to as homosexuals are actually bisexual. They indulge in both hetero-sexual and homo-sexual activity. Other women mentioned knowing about bestiality, "I saw my young brother-in-law do it with the donkey. When his mother realized I had seen him she told me not to come down to the stables in the morning, she'd 
handle the work there". Others mentioned knowing about masturbation and wet dreams.

\section{Linking Reproductive Tract Infections to Sexuality}

Women were asked several questions on their perception of reproductive morbidities and the causes of infection and how reproductive tract infections are transmitted. Fourteen out of forty-one women associated infections with pregnancy and childbirth. They did not mention specific infections but they perceived that consecutive pregnancies could be the cause for some of the infections they get. Other causes mentioned for infections were: a disease that is present in the liquid a man ejaculates (semen), lack of genital cleanliness among men and women, use of unhygienic rags during menstruation, use of indigenous remedies, and promiscuous sex. Other diseases such as Schistosomiasis and Cancer were also mentioned as the causes for reproductive tract infections among women. Only one respondent did not associate infections with anything. She said infections are not caused by anything, they just happen.

In probing further to elaborate on the mechanisms of transmission of infection, more than half of the women mentioned intercourse as the main channel of transmitting reproductive tract infections. Some women were more specific than others. They believed that the disease is found in the liquid men ejaculate (semen). Others said once men complain of a burning sensation during urination, that is the time disease is transmitted during intercourse. When asked who is more vulnerable to contracting the infection, fourteen of the respondents said women were more vulnerable because men are responsible for infecting women, while nineteen said both men and women could infect each other and both are vulnerable to catch the infection. Eight women did not know that certain diseases are transmitted through sexual intercourse, and claimed not to have heard of any disease that could be transmitted from man to woman or vice versa.

When women were asked openly whether they had heard or knew about 
sexually transmitted diseases, the majority of respondents (29) claimed not to know any. The large majority (27) of the women who reported not to know were illiterate, while only one respondent with a university education reported not knowing. This respondent was raised and educated by nuns at a school attached to a monastery close to Cairo. Other variables such as age, employment of women, migration of husband, did not indicate any relationship with knowledge of sexually transmitted diseases. However, it was noticed that women married to blue collar employees and certain skilled labourers in urban areas are more knowledgeable and aware of sexually transmitted diseases. Out of these women, four were married to employees and seven to skilled labourers. These women reported knowing about sexually transmitted diseases. Skilled labourers and employees are employed by either government or private companies mostly in urban areas. They also would be more educated and are eventually more exposed to health information. On the other hand, the large majority of women married to agricultural workers or unskilled labourers reported not to know.

When the question was put differently and respondents were asked to name some of the sexually transmitted diseases they knew or had heard of recently, only six respondents specifically mentioned Syphilis and Gonorrhea. Other respondents (7) referred to infections without specifying or naming any particular infections, while three reaffirmed their belief that Cancer and Schistosomiasis are sexually transmitted. This perception could be due to the fact that since men who have Schistosomiasis bleed from their penis and women bleed from the same path when they menstruate hence they transmit disease through intercourse. Cancer on the other hand is feared by all Egyptians. Like many people in this region they refer to Cancer as El Marad El Khabeess (The malicious disease) without mentioning its name. The lack of knowledge and information concerning Cancer enhances the perception that it is a contagious disease and it could be transmitted by intercourse since most of the cases they know of are connected to genital organs, (uterus and vagina for women, and prostate and urethra for men).

Respondents were further asked how they could protect themselves from contracting sexually transmitted diseases. The majority referred to curative 
methods such as consulting physicians (23) and some indicated using traditional or indigenous methods, whenever they recognize a symptom. Nine respondents perceived of preventive methods as appropriate. Only six women mentioned avoiding sexual relations, three of them said to refrain from intercourse with the husband whenever he complains of symptoms they associate with sexually transmitted diseases, and three respondents said to refrain from extra-marital relations. The other cases claimed that hygiene and cleanliness, especially of genital organs, could protect them from contracting infections. Only one respondent showed a fatalistic attitude. She commented in answer to the question, "Protection comes from God, there is nothing for me to do".

Consequently, when women are faced with a health problem related to their reproductive tract, they may endure it silently and may also endure the sex demands of the husband without uttering a complaint, not knowing that some sexuality problems like Asynodia (El Ena'ah) and some sexually transmitted diseases like Granulosis (habaab) can be a case for divorce. If Islamic jurisprudence gives women the right to ask for divorce in cases of impotence and certain sexually transmitted diseases, would not Islamic jurisprudence allow them to refuse sex with their husbands who are suspected of having infections and need to be treated?

\section{SUMMARY AND CONCLUSIONS}

We cannot ignore the urgent need for more research on sex behavior as a basic requirement for improving reproductive health in our region. The myth that sexuality is a taboo has no grounds since women over the centuries have been discussing their sexual lives among themselves. Moreover, the attitude of Islam, the religion of the majority in Egypt, to sexuality is relaxed and not puritanical. Islam says sexuality is to be enjoyed, but only within the marriage institution for both men and women. All forms of sexuality are openly discussed in the Qur'an and the Hadith, such as the husband-wife 
relationship, intercourse, menstruation, homosexuality, bestiality, anal sex and so on.

Islam's positive and relaxed attitude to sexuality will enable us to approach education in this sphere through religious teaching. It is known that both women and men consulted the prophet on sexual matters since it was necessary for them to be sure that they were following the precepts laid down. For example, when a woman consulted Omar Ibn ElKhattab, the second caliph, about her sexual needs in her husband's absence, he issued a decree that men were not to be absent from their wives for more than four months; a wife should not be deprived of sexual life for longer than that. If Islamic teaching were strictly followed, labourers who leave their home country for work, should not be asked to leave their wives behind for the same reason. The teaching of the Qur'an on all sexual matters is conveyed to pupils in schools under the jurisdiction of $\mathrm{Al}$ Azhar. For example, in their lessons on fikh al Islam (Islamic doctrine) they are taught that a man should not approach a menstruating woman for sex. Furthermore, a Muslim woman may not pray while bleeding since this precludes a state of cleanliness. In other words religious teaching can provide an avenue for enlightenment on sexual matters and is not an obstacle.

The importance of such education and enlightenment has been underlined by recent research into reproductive morbidity which has indicated the existence of sexually transmitted diseases. To prevent and control reproductive tract infections nowadays is quite possible. Prompt recognition and treatment of these often curable conditions provide an opportunity for improving women's reproductive health (Wasserheit 1990). Yet, women need to know the signs and symptoms of these infections; they need to know the high risk behavior that causes them. They need empowerment to seek medical help. Our study confirmed the fact that, once rapport is established, discussing sexuality is not a taboo among rural women. With the first question on sexuality, we opened the flood gates. Most women were relieved that they could finally talk about their sexual concerns and fears to someone who knows and cares. Their questions, however, indicated a lack of knowledge on body functions, on the physiology of reproduction and on 
reproductive tract infections.

This finding, that lack of awareness of symptoms prevents women from seeking needed medical help, was not a surprise. What was, although it probably should not have been, was the women's enjoyment of sex. For reasons that are not obvious, an assumption has existed that among relatively uneducated people sex is mainly the prerogative of men, a vehicle for their physical satisfaction and no more. This notion of women unwillingly succumbing to their husbands' often unreasonable demands proved to be completely erroneous. These rural women associate sex with love and tenderness. They enjoy their sexual life and are happy and proud of the love which sex with their husbands expresses. They make no attempt to hide signs such as washing their hair or having a bath which are often indications of post-sex purification. They like to show the community that they are the focus of their husband's desire because, in most cases, they regard it as an expression of love and affection. As we have pointed out, there are exceptions. Some husbands were accused of being rough and over-demanding, but for many women an enjoyable sexual relationship was the criterion for judging a man. A "good" husband is an affectionate and sexually considerate husband.

The "rites de passage" that move girls from childhood to womanhood emphasize her role as a wife and as a mother, and are essentially based on sexuality inspite of the fact that existing cultural norms require them to demonstrate modesty and ignorance of sex-related topics. For instance female circumcision, the first phase in the initiation of girls into womanhood, submits them to an operation which is meant to make their external genitals look different from the other sex, to make them more appealing and more pleasurable to men. Cutting the labia and part of the clitoris at an early age is also perceived as a restraint to sensuality before marriage. It was quite obvious from our research that women's attitudes towards female circumcision is not negative. Some women still recall the pain after the operation, but none of them perceives of it as body mutilation or aggression against their sexuality. The fact that so many women expressed pleasure in their sex-life should lead us to investigate assumptions 
concerning the consequences of female circumcision. Apparently what is done to most women in the community we studied does not seem to prevent them from satisfaction in their sexual life. Perhaps the operation has become very minor. Indeed, in subsequent research in Damietta, doctors were often unable to tell whether a woman had been circumcised or not. These women insisted that they had been circumcised. Could it be that there is regeneration? More research is needed to help us find the right approach in ending this unnecessary practice. We need to discuss what gives a woman her identity as a woman with both women and men. They need to be convinced that this operation is not necessary for a woman's femininity. Although we have not come across cases of men divorcing a woman who is not circumcised, we nevertheless need to address the cultural perception that for a woman to be marriageable she should be circumcised. We cannot impose pressure from outside the society itself. On the contrary it has to come from within the community. What is needed is a holistic approach whereby politicians, religious leaders, health practitioners (formal and indigenous), and health educators should come together and make an effort to design programs for creating awareness and educating men and women in order to enhance change in perceptions, attitudes and behavior towards this practice.

The second "rite de passage" in the initiation of girls to womanhood is the onset of menarche. Following the first menstruation girls are congratulated on reaching womanhood and are offered some information on how to manage menstruation and how to cleanse or purify themselves from the state of impurity in accordance with Islam. With the onset of menarche girls get their first experience with pronounced sex differentials. They are instructed not to play with boys or associate with them and they are confined to the household and its chores. Except for those who work as agricultural labourers, young girls are not allowed to do jobs that take them to secluded places or in close proximity to men. The talk about the importance of virginity and chastity becomes more condensed and more frequent including threats of severe punishment in case of violation. From then on, girls start to become more aware of sexuality and begin to store bits and pieces of 
information from hearsay and from what they see around them. Some girls, however, do not seem to be informed about menarche beforehand. They are very frightened by the blood which they associate with the taboos on premarital relationships. They are afraid that they have somehow transgressed. This frightening ignorance must be addressed since this fear can be carried over into the marital relationship, especially for very young girls creating a fear of their sexual relation with their husband.

The third "rite de passage" which actually transfers girls to womanhood is deflowering on the wedding day. To many of our respondents, deflowering was reported as a traumatic experience despite the fact that they were told that it should be the best day of their lives. Girls are thrown bluntly into the experience of intercourse. Breaking the hymen of the bride with the forefinger (by groom or daya) is meant to ensure and announce the virginity of the bride and although many of the respondents were happy to please their relatives and in-laws regarding their virginity, yet most of them still recall the pain, the discomfort and the fear of that episode. The respondents who reported a traumatic deflowering experience, also complained of frigidity and sexual problems with their spouses. The deflowering celebration is another of the harmful practices in Egyptian culture, not only because of the undignified treatment, the fear and the pain women experience, but also because they are thereby programmed into submission to husbands' demands for sexuality. During the wedding night or the preparations for it, close relatives may jokingly insinuate that sexuality within marriage denotes a husband's love and desire, they may also allude to the pleasure women get from intercourse, but what women hear most are instructions on how to obey their husband and how to respond promptly to his needs and demands. All the duties within the marriage institution are recited to them, but none of their rights are mentioned, hence, women enter this new relationship feeling subservient and insecure.

Educating men and women about their bodies could help in curbing certain practices of high-risk sexual behavior. Accurate information on abnormal gynecological symptoms may also help women detect and identify certain reproductive tract infections (including sexually transmitted diseases) and 
encourage them to take measures of prevention and treatment. Informing women of religious doctrine regarding reproductive health, informing women of their rights and not only their duties in sexuality within marriage, may empower them to seek help and to stand up for their rights to respectful protection of their health. It would help women to take prompt measures to treat any reproductive tract morbidity they might encounter without feeling guilty of depriving the husband of his allegedly sacred sexual rights. Both women and men stand to gain from greater knowledge, both knowledge about their bodies and how they function as well as knowledge of Islamic teachings which offer protection to women. Lessening the burden of reproductive ill health is to the advantage not only of women, but of their husbands and children too. Contextualizing reproductive health programmes within socio-cultural realities is a necessary mechanism for ensuring their acceptance.

Finally, we would like to emphasize those points that must inform our future activities. There is a need for more research on sexuality in our region for two main reasons. The first one is the importance of reproductive health in health and population policy, especially in the wake of the ICPD (Cairo 1994), and our own research. Greater knowledge of sexuality and patterns of sexual behavior can positively affect contraceptive practice, control and prevent STD's and enhance general sexual well-being. The second reason for further research is that health education in the specific area of reproductive health needs to be based on research and understanding as opposed to prior assumptions concerning patterns of sexual behaviors and women's perceptions of their bodies and body functions.

A second point which is of pivotal importance in influencing our activities is the positive perspective of sexuality provided by Islam. Islamic teaching can provide the context within which education about sexuality can be approached in our culture, especially that women find it easy to discuss this subject provided proper rapport is established. In particular the three rites of passage for women in Egypt, circumcision, the onset of menarche and defloration must each be a focus of attention in order that the women of our region may reap that maximum benefit from our research. 


\section{References}

Abou-Zeid, A.M. (1965). Honour and Shame among the Bedouins of Egypt. In, Honour and Shame: The Values of Mediterranean Society, Eds. J.G. Peristiany, Weidenfeld and Nicolson, London.

Al Shafe'i, I.H. (1880). Fatah Al Bari bishar'h Sahih Al Bokhari. Boulak, Cairo.

Assaad, M. (1980). Female Circumcision in Egypt: Social implications, Current Research and Prospects for Change. Studies in Family Planning, Vol. 11, No.1.

Bateson, G. (1947). Sex and Culture. Ann. New York Academy of Science, XLVII, 647.

Bourquia, R. (1990). The Woman's Body : strategy of illness and fertility in Morocco. Paper prepared for workshop organized by Johns Hopkins University, The Ford Foundation and the Population Council, Towards more Efficacy in Women's Health and Child Survival Strategies : Combining Knowledge and Practical Solutions. Cairo.

Elias, C. (1991). Sexually Transmitted Diseases and the Reproductive Health of Women in Developing Countries. Working Papers No. 5. The Population Council, New York.

Evans, J. et al. (1987). Women and Children in Poverty: Reproductive health and child survival. Report to the trustees of the Ford Foundation for its mid-decade review of programs. The Ford Foundation, New York.

Fathalla, M. (1988). Research Needs in Human Reproduction. In, Research in Human Reproduction, Biennial Report 1986-1987, Eds. E. Diczfalusi, P.D. Griffin and J. Khanna. WHO, Geneva.

Germain, A. (1987). Reproductive Health and Dignity : Choices for third world women. Technical background paper for The International Conference on Better Health for Women and Children through Family Planning. Nairobi.

Hassan, R. (1994). An Islamic Perspective. In, Women Religion and Sexuality, Ed. Jeanne Becher. WCC Publications, Geneva, pp. 95-128.

Karim, M. and R. Ammar. (1965a). Complications of Female Circumcision. Gazette of the Egyptian Society of Gynecology and Obstetrics, Vol. 15, No. 2.

Karim, M. and R. Ammar. (1965b). Female Circumcision and Sexual Desire. Ain Shams Press, Cairo.

Khatib, M. (1950). Khotab Al Rasul. Dar al Fadila. Cairo. 1946/1986. p.122.

Khattab, H. (1978). Role and Status of Women and their Fertility Behavior. Paper.presented to the Conference on Women's Civil Law and Fertility Behavior, Cairo.

Khattab, H. (1983). The Egyptian Site. In, Patterns and Perceptions of Menstrual Bleeding, Eds. Robert Snowden and Barbara Christian. Croom Helm, London.

Khattab, H, and S. El-Katsha. (1987). Promotion of the Role of Women in Water and Environmental Sanitation Services. A Demonstration Project. UNDP, Cairo. (November).

Khattab, H. (1992). The Silent Endurance. Social conditions of women's reproductive health in rural Egypt. UNICEF, Amman, Jordan. 
Khattab, H., H. Zurayk, N. Younis and O. Kamal. (1994). Field Methodology for Entry into the Community. The Policy Series in Reproductive Health No. 3. The Population Council. Cairo, Egypt.

Kinsey, A., W. Pomeroy and C.E. Martin. (1948). Sexual Behavior in the Human Male. Saunders, Philadelphia.

Kinsey, A., W. Pomeroy, C.E. Martin and R.H. Gebhard. (1953). Sexual Behavior in the Human Female. Saunders, Philadelphia.

Mahmoud, S. T. (1988). Mota'a Al 'Arouss. Dar Al Iman, Alexandria.

Malinowski, B. (1929). The Sexual Life of Savages in North Western Melanesia. Halcyon House, New York. 1941 (original edition 1929).

Masters, W.H. and V.E. Johnson (1966). Human Sexual Response. Little Brown, Boston. Mead, M. (1923). Coming of Age in Samoa. Morrow, New York.

Meinardus, O. (1967). Mythological Historical and Sociological Aspects of the Practice of Female Circumcision among the Egyptians. Acta Ethnographica Academiae Scientiarum Hungaricae. Reprint, pp.387-397.

Murdock, G.P. (1949). The Social Regulation of Sexual Behavior. In, Psychosexual Developments in Health and Disease. Eds. P.H. Hoch and J. Zubin. Grune and Stratton, New York. p.256.

Myntti, C. (1988). Hegemony and Healing in Rural North Yemen. Social Science and Medicine, Vol. 27, No. 5. pp. 505 - 520.

Peiss, C. et al. (Eds.). (1989). Passion and Power: Sexuality in History. Philadelphia, Temple University Press.

Sabek, S. (1990). Fik'h Al Sunna. Dar al Fat'h lil Islam al 'Arabi, Cairo.

Snowden, R. et al. (Eds.). (1983). Patterns and Perceptions of Menstruation. Croom Helm, London.

The Holy Qur'an. (1983). Text, Translation and Commentary. A. Yusuf Ali. Amana Corp. Publisher, Brentwood, Maryland.

Vance, C. (1991). Anthropology Rediscovers Sexuality : A Theoretical Comment. Social Science and Medicine, Vol. 33, No. 8, pp. 875-884.

Wasserheit, J. (1990). Reproductive Tract Infections. In, Special Challenges in Third World Women's Health, Presentations at the 117th Annual Meeting of the American Public Health Association, Chicago, Illinois, October 1989. International Women's Health Coalition, New York.

Weeks, J. (1977). Coming Out: Homosexual Politics in Britain from the 19th Century to the Present. Quartet Books, London.

Weeks, J. (1981). Sex, Politics and Society. The Regulation of Sexuality since 1800. Longman, New York.

Working Group on Reproductive Health (1988). Study on Reproductive Morbidity in Rural Giza, Egypt. 1988-1991. The Population Council. Cairo, Egypt.

Younis, N., H. Khattab, H. Zurayk, M. El-Mouelhy, M. Fadle Amin and A. M. Farag. (1993). A Community Study of Gynecological and Related Morbidities in Rural Egypt. Studies in Family Planning, Vol. 24, No. 3, pp.175-186. 
Zalduondo, B.O. and J. M. Bernard. (1993). Sexual Economic Exchange in Urban Haiti : Culture, Gender and Sexual Risk Behavior. Paper presented at the ARHN Working Group on Sexual Behavior Research, Conference on International Perspectives in Sex Research Rio de Janeiro, 22-25 April, pp. 1-49.

Zurayk, H. (1988). A Framework of Ideas for Development of a Research Agenda for the Working Group on Reproductive Health. Paper presented at first meeting of Working Groups of the Population Council Special Program of Research and Technical Consultation on Family Resources, Child Survival and Reproductive Health, Cairo. 


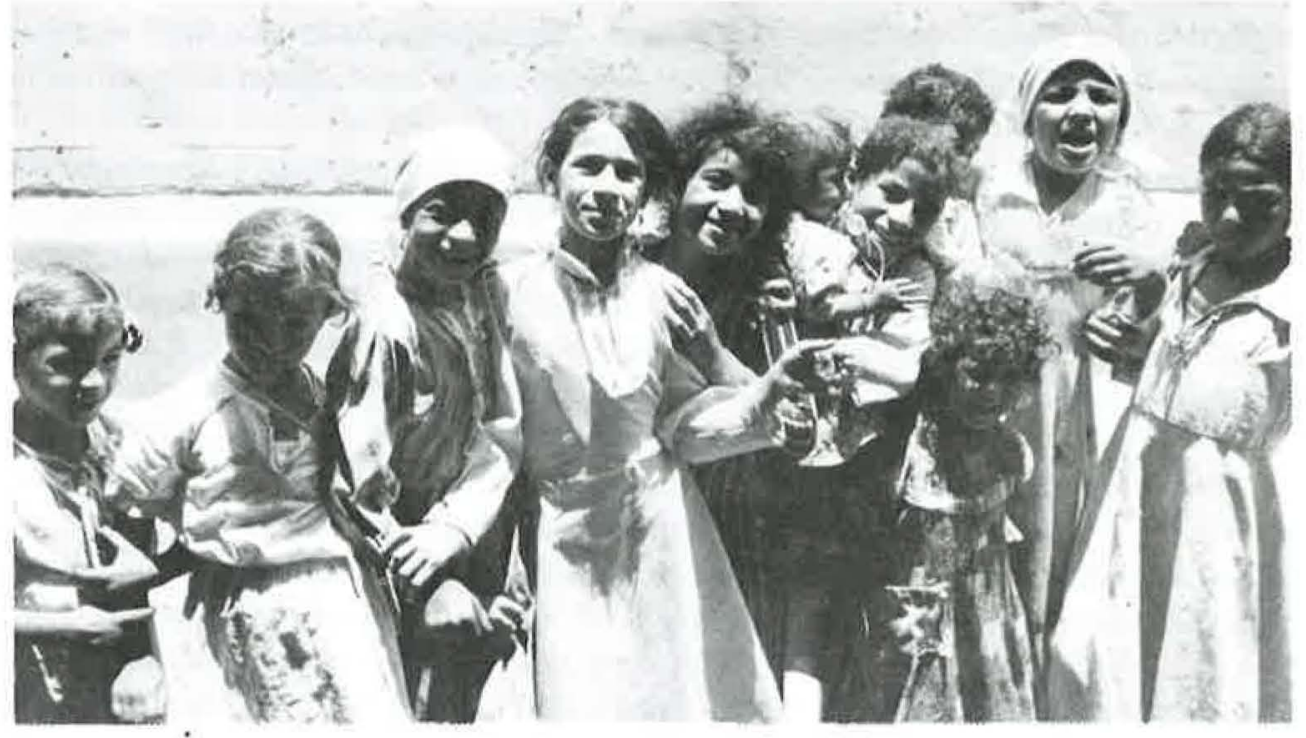

Above: Girls at the age when circumcision is performed.

Below: Girls at the age of onset of menarche.

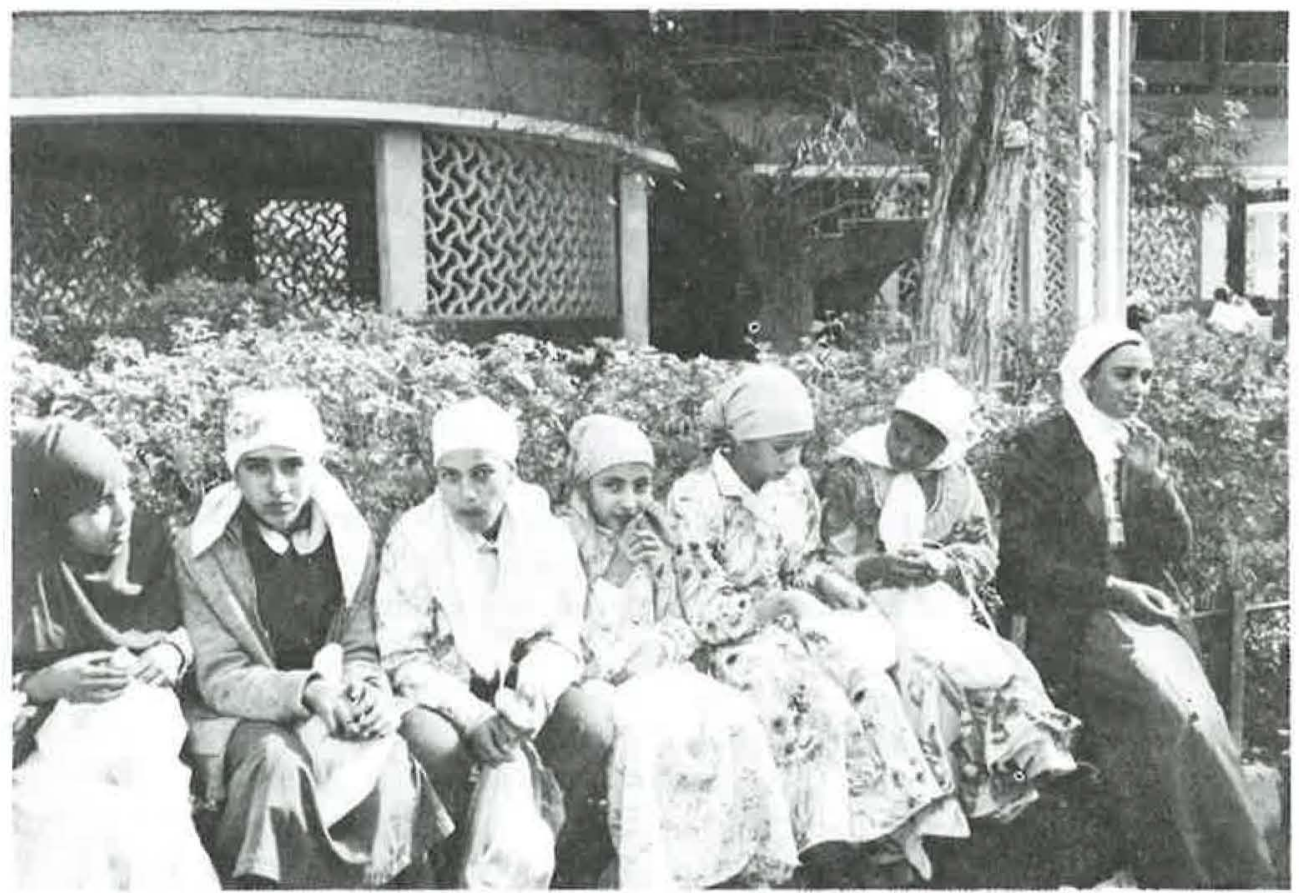




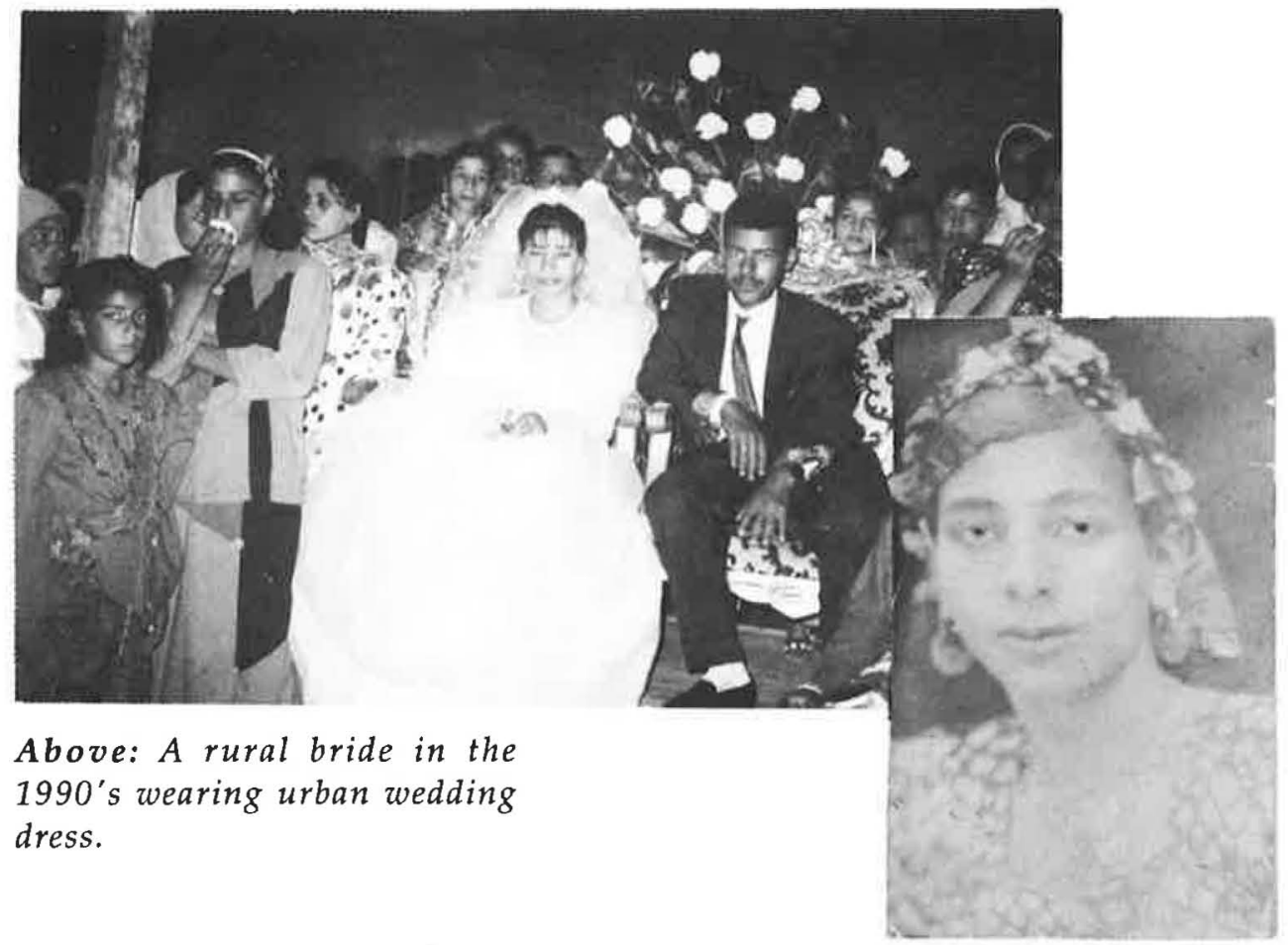

Below: Morning after wedding (sabahiya) both families come to congratulate bride and groom.

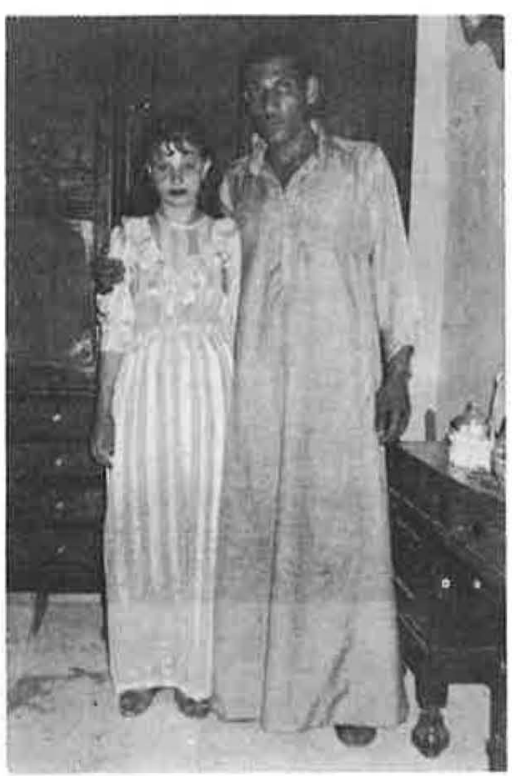

Above: A rural bride in the 1960's wearing a colourful head cover (mandil). Notice jewellery worn by bride (gold earings and necklace).

Below: Guests waiting to announce the virginity of the bride.

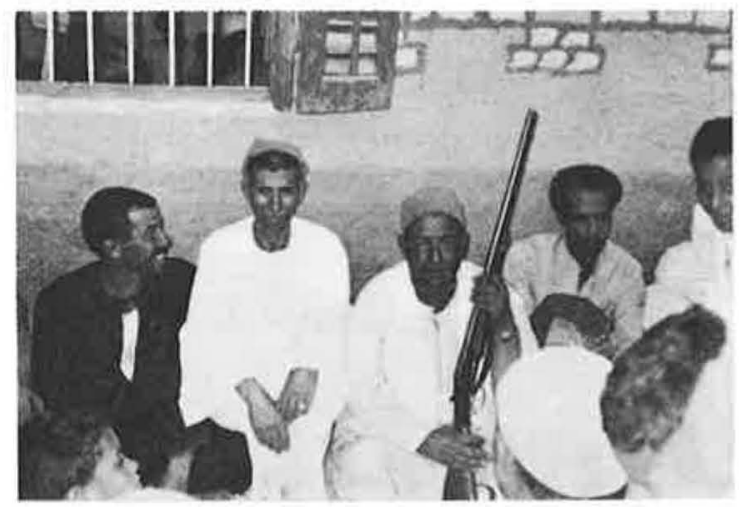




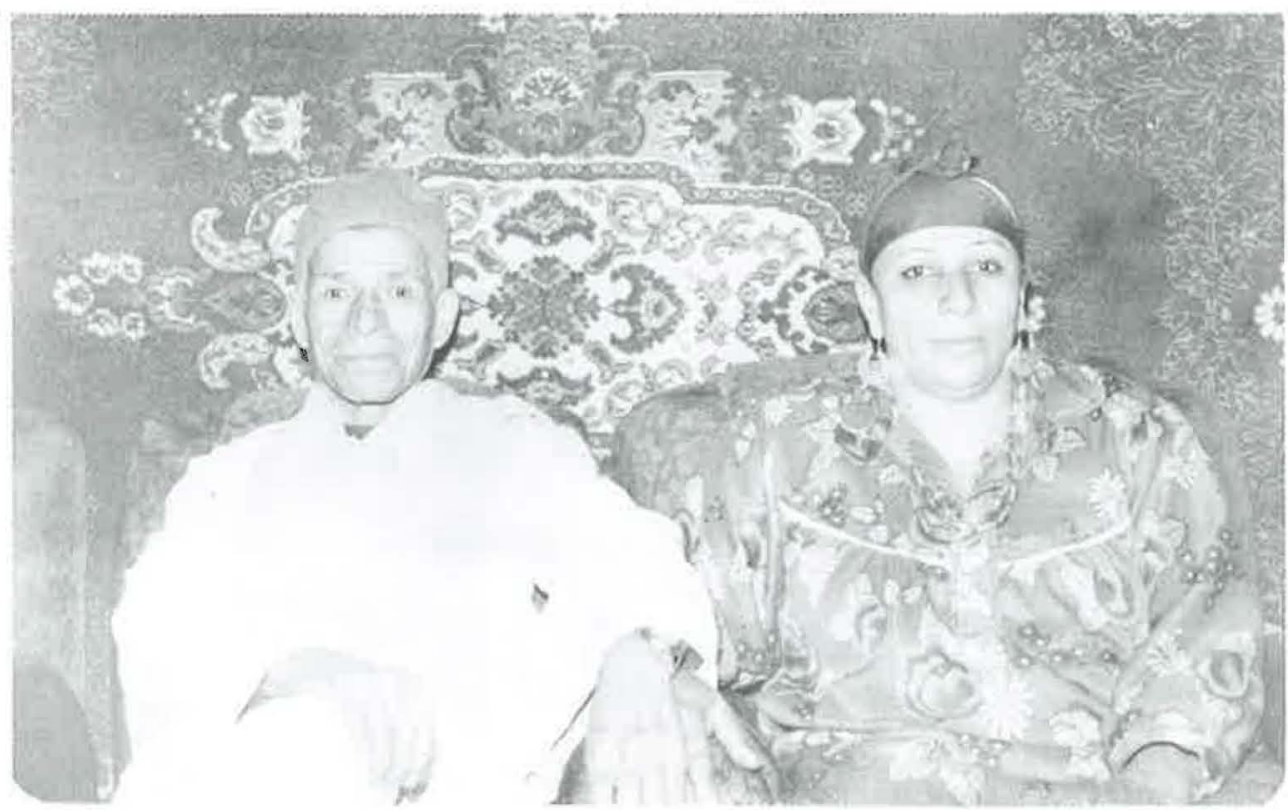

Display of affection by peasant husbands. Older couples are not shy to demonstrate their affection.

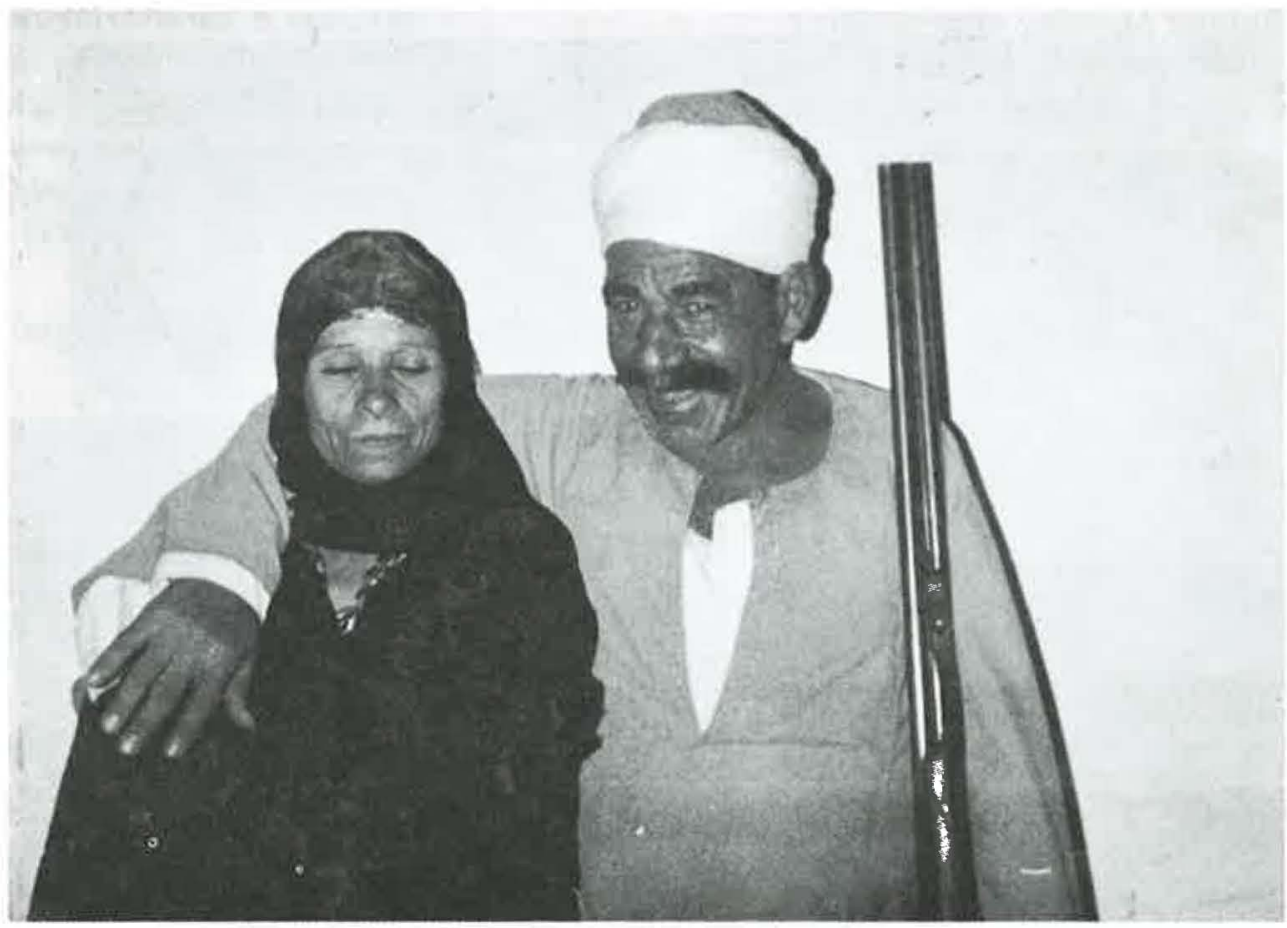


The Population Council

Regional Office for West Asia and North Africa

P.0. Box 115, Dokki, Giza, Egypt 